\title{
Assessing the Impacts of Non-Ricardian Households in an Estimated New Keynesian DSGE Model
}

RiCARDO MARTOa

JEL-Classification: C11, E12, E37, E52, E62

Keywords: DSGE, New Keynesian model, non-Ricardian households, Bayesian inference, Portugal

\section{Introduction}

Since the appeal of Mankiw (2000) for the inclusion of rule-of-thumb consumers in macroeconomic models, several papers have attempted to do so. Most have calibrated their proportion, others have estimated it, but very few have attempted to analyze the impacts of different specifications on the overall model predictions. Galí, López-Salido, and Vallés (2004) assess the impact of different calibrated shares of rule-of-thumb consumers on the interest rate rule equilibrium properties and Galí, López-Salido, and Vallés (2007) extends this analysis by studying equilibrium dynamics when the level of price stickiness varies. The latter also provides a partial analysis of the impact of different shares of rule-ofthumb consumers. This paper builds on these findings.

The paper presents and estimates a standard New Keynesian (NK) dynamic stochastic general equilibrium (DSGE) model of the Portuguese economy allowing for two types of households like in Galí, López-SALIdo, and Vallés (2007): Ricardian (or optimizing) households and non-Ricardian (or liquidityconstrained or rule-of-thumb) households. The former maximize their expected lifetime utility over consumption and leisure and they have complete access to capital markets in order to smooth consumption over time. The latter are constrained to choose a combination of consumption and leisure maximizing their per period utility subject to their disposable income per period. The model adds

a Inter-American Development Bank (IDB). E-mail address: rmarto@iadb.org. I am grateful to Toru Kitagawa, Vincent Sterk, Riccardo Constantini, and Hector Conroy for their valuable inputs. Useful insights from the lectures of Paul Levine and Bo Yang given at the NIPE's 9 th summer school are duly acknowledged. The views expressed in this paper are mine and should not be interpreted as reflecting the views of the IDB. Any errors or shortcomings are my responsibility. 
several frictions and shocks to GaLí, López-SALIdo, and VALLÉs (2007), namely: a consumption habit to Ricardian households and price indexation to the intermediate goods firms not allowed to reoptimize prices in a Calvo (1983) price setting scheme. ${ }^{1}$ It also adds five other shocks: an investment efficiency shock and a consumption preference shock on Ricardian households; a labor-augmenting productivity shock on intermediate goods firms technology and a price markup shock on their costs; and, a monetary policy shock in the Taylor-type interest rate rule.

The choice of a NK model is relevant because it adds nominal rigidities, imperfections and other frictions to the standard Real Business Cycle (RBC) model with the aim of reproducing some important stylized facts these fail to consider: monetary policy is given a pertinent role in influencing short-run real variables with the introduction of price stickiness in the form of staggered prices $\grave{a}$ la Calvo (1983) or à la TAYLOR (1980) and economic stabilization policies are made relevant to counteract cyclical fluctuations generated by imperfections and frictions. These standard flexible-price models are unable to explain the sluggish adjustment of prices and to capture the large and persistent response of output, as well as the increase in labor productivity after a monetary policy shock. YUN (1996) and Christiano, Eichenbaum, and Evans (2005) introduced indexation that has successfully captured inflation persistence and the delayed peak response of inflation to a monetary policy shock. In addition, the response of private consumption to a government spending shock is estimated to be negative in the standard RBC model, although several papers using vector autogressions (VAR) have pointed to a positive (PеRотt, 2004) or at best insignificant (MountFord and Uhlig, 2004) response of private consumption - the bulk of papers tends to favor the Keynesian hypothesis that in normal times consumption responds positively to a rise in government spending. ${ }^{2}$

The inclusion of rule-of-thumb consumers is meant to capture the impact of fiscal policy shocks on private consumption by introducing heterogeneity in consumers. This is motivated by the failure of the permanent income hypothesis, showing that private consumption depends heavily on current income. ${ }^{3}$ GaLí,

1 Consumption habits were added, as in AвEL (1990), to capture the persistence in output and consumption present in the data. Other features include wage stickiness as in ErCEg, HeNDerson, and Levin (2000) and investment costs as in Bernanke, Gertler, and Gilchrist (1999) or SMETS and Wouters (2003).

2 Note, however, that Perotti (1999) provides evidence of a negative response to government spending in periods of large fiscal consolidations.

3 Galí, López-Salido, and Vallés (2004) find that an interest rate rule that satisfies the Taylor principle (i.e. the short-term nominal interest rate must respond more than proportionally to 
López-SAlido, and Vallés (2007) extended the standard sticky-price model with deficit financing by incorporating optimizing and rule-of-thumb consumers. They show that their calibrated model can account for the government spending shock impact on private consumption. As opposed to Galí et al., Coenen and Straub (2005) estimate the fraction of non-Ricardian households in the Smets and Wouters model and consider a more complete fiscal policy framework. They point to a relatively small share of liquidity-constrained households in the euro area and to a slight response of consumption to a government spending shock with a distortion of Ricardian households intertemporal consumption decision their willingness to smooth consumption over time decreased. ${ }^{4}$ At odds with the empirical literature is what Afonso and Sousa (2011) found after estimating a Bayesian Structural VAR using data for Portugal, reporting that a government spending shock has a crowding out effect on private consumption.

Lastly, this paper intends to add to the existing literature a comprehensive assessment of the effect of non-Ricardian households in a DSGE model. It sheds light on the impact of different fractions of non-Ricardian households on the computation of posterior distributions of parameters, impulse response functions, variance and historical decompositions. Hence, this paper clarifies the importance of choosing appropriately the share of rule-of-thumb consumers by showing that different specifications may significantly alter overall results and conclusions. Furthermore, it should be regarded as an attempt to define the share of non-Ricardian households in the Portuguese economy. To the best of my knowledge, this is the first study that estimates it. ${ }^{5}$

The remainder of the paper is organized as follows: Section 2 describes the model economy; Section 3 presents the calibrated parameters and priors defined for the Portuguese economy; and for alternative specifications of non-Ricardian households Section 4 analyzes posterior estimates, the responses of output growth, inflation, and short-term nominal interest rate to structural shocks, as well as their sources of fluctuations. Section 5 concludes the paper.

a change in inflation) for a given proportion of rule-of-thumb consumers is not sufficient to ensure the unique equilibrium of the interest rate rule.

4 Forni, Monteforte, and Sessa (2009) add non-Ricardian households to Christiano, Eichenbaum, and Evans (2005) and conclude that fiscal policy has a mild effect on private consumption.

5 Almeida, Castro, and Félix (2010) present a dynamic general equilibrium model with calibrated non-Ricardian consumers (at $40 \%$ ) to assess the effects of increasing competition in the labor market and in the non-tradable goods sector. 


\section{The Model Economy}

Based on Galí, López-Salido, and Vallés (2007), this New Keynesian model incorporates two different types of households: Ricardian and non-Ricardian. The model economy also features three other types of agents: final goods (or retail) firms and intermediate goods (or wholesale) firms; and a monetary authority, represented by the central bank, which is independent of the fiscal authority, the government.

In order to derive a system of non-linear stochastic difference equations defining the DSGE model, agents preferences, the economy's technological constraints, and the exogenous shocks affecting the economy need to be specified. Agents decision rules are derived from the first-order conditions of their (dynamic) optimization problem. Assuming that markets clear and aggregating over agents, the model is then written in a log-linearized form. ${ }^{6}$

\subsection{Households}

The economy is populated by a continuum of infinitely-lived households, which may be of two types: a proportion $(1-\lambda)$ is a Ricardian household, which maximizes its expected lifetime utility over consumption and leisure and which has complete access to capital markets in order to smooth consumption over time; on the other hand, a fraction $\lambda$ is a non-Ricardian household constrained to consume its disposable income each period. However, I allow the non-Ricardian consumers to optimally choose a combination of consumption and leisure per period.

Both types of households are assumed to consume non-differentiated consumption goods and to supply non-differentiated labor to firms. Total consumption is given by $C_{t}=(1-\lambda) C_{1, t}+\lambda C_{2, t}$ and total labor supplied defined as $N_{t}=(1-\lambda) N_{1, t}+\lambda N_{2, t}$, where $C_{1, t}$ and $N_{1, t}$ are aggregate consumption and labor supply of Ricardian households, and $C_{2, t}$ and $N_{2, t}$ aggregate consumption and labor supply of liquidity-constrained consumers, respectively.

\subsubsection{Ricardian Households}

\section{Preferences}

A representative Ricardian household, indexed by $i \in[0,1-\lambda)$, maximizes its expected lifetime utility over consumption and leisure as

6 Derivations and log-linearized equations are provided in the Appendix. 


$$
\mathbb{E}_{t} \sum_{s=0}^{\infty} \beta^{s} U\left(C_{1, t+s}(i), N_{1, t+s}(i)\right)
$$

In particular, at time $t$ it derives utility from consuming goods $C_{1, t}$ net of an external consumption habit $H_{t}$, and from leisure $L_{1, t}$ defined as $L_{1, t}=1-N_{1, t}$ :

$$
\mathbb{E}_{t} \sum_{t=0}^{\infty} \beta^{t}\left(\frac{\exp \left(v_{t}^{d}\right)\left(\left(C_{1, t}(i)-H_{t}\right)^{(1-\rho)}\left(1-N_{1, t}(i)\right)^{\rho}\right)^{1-\sigma_{c}}-1}{1-\sigma_{c}}\right),
$$

where $\beta \in(0.1)$ is the household's rate of time preference, $\sigma_{c}$ is the inverse of the intertemporal elasticity of substitution and $\rho$ is a preference parameter over consumption and leisure. The external consumption habit is defined as a proportion of lagged aggregate Ricardian households consumption $H_{t}=\chi C_{1, t-1}$, with $\chi$ measuring the degree of habit persistence. $v_{t}^{d}$ is a consumption preference shock defined by the $\operatorname{AR}(1)$ process $v_{t}^{d}=\rho_{d} v_{t-1}^{d}+\varepsilon_{t}^{d}$, where $\varepsilon_{t}^{d} \sim \mathrm{N}\left(0, \sigma_{d}^{2}\right)$.

\section{Budget Constraint}

Ricardian households face the following intertemporal real budget constraint:

$$
C_{1, t}(i)+I_{1, t}(i) \leq \frac{W_{t}}{P_{t}} N_{1, t}(i)+R_{t} K_{1, t}(i)-T_{1, t}(i)+D_{1, t}(i)
$$

where on the left-hand side we have the household's expenditures and on the right-hand side the household's disposable resources. $I_{1, t}$ denotes the investment made by the household in period $t$ in real terms, $W_{t}$ is the nominal wage from a perfectly competitive labor market, $P_{t}$ the price index and $R_{t}$ the real interest rate on capital. $T_{1, t}$ denotes lump-sum taxes and $D_{1, t}$ are dividends from monopolistic firms owned by Ricardian households, both expressed in real terms.

The accumulation of capital by the Ricardian household evolves according to:

$$
K_{1, t+1}(i)=(1-\delta) K_{1, t}(i)+\exp \left(v_{t}^{i}\right)\left[1-S\left(\frac{I_{1, t}(i)}{I_{1, t-1}(i)}\right)\right] I_{1, t}(i)
$$

where $K_{1, t+1}$ is the capital stock owned by Ricardian households at the beginning of period $t+1$ (or end-of-period $t$ capital stock), equivalent to the capital 
stock net of a time-invariant depreciation rate $\delta \in[0,1]$ at the beginning of period $t$ and the investment made during this period net of a non-negative adjustment cost. Following SMETS and Wouters (2007), the adjustment cost function satisfies $S(1)=S^{\prime}(1)=0$ and $S^{\prime}, S^{\prime \prime} \geq 0$, and has the convenient property that investment costs disappear in the long-run. Its functional form is given by $S\left(X_{t}\right)=\phi_{X}\left(X_{t}-1\right)^{2}$, where $\phi_{X}$ is an adjustment cost parameter. Moreover, investment is subject to an efficiency shock $v_{t}^{i}$, which follows an $\mathrm{AR}(1)$ process $v_{t}^{i}=\rho_{i} v_{t-1}^{i}+\varepsilon_{t}^{i}$, where $\varepsilon_{t}^{i} \sim \mathrm{N}\left(0, \sigma_{i}^{2}\right)$.

\section{Optimality Conditions}

Solving the household's maximization problem leads to the following first-order conditions:

(i) the consumption Euler equation (i.e. the intertemporal consumption/savings decision)

$$
U_{C_{1, t}}(i) Q_{1, t}(i)=\beta \mathbb{E}_{t}\left[U_{C_{1, t+1}}(i)\left(R_{t+1}+Q_{1, t+1}(i)(1-\delta)\right)\right] ;
$$

(ii) the labor supply equation (i.e. the intratemporal consumption/leisure decision)

$$
\frac{U_{N_{1, t}}(i)}{U_{C_{1, t}}(i)}=-\frac{W_{t}}{P_{t}} ;
$$

and, (iii) the Ricardian household's investment decision

$$
\begin{gathered}
Q_{1, t}(i) \exp \left(v_{t}^{i}\right)\left[1-S\left(\frac{I_{1, t}(i)}{I_{1, t-1}(i)}\right)-S^{\prime}\left(\frac{I_{1, t}(i)}{I_{1, t-1}(i)}\right) \frac{I_{1, t}(i)}{I_{1, t-1}(i)}\right]+ \\
\beta \mathbb{E}_{t}\left[Q_{1, t+1}(i) \frac{\lambda_{1, t+1}(i)}{\lambda_{1, t}(i)} \exp \left(v_{t+1}^{i}\right) S^{\prime}\left(\frac{I_{1, t+1}(i)}{I_{1, t}(i)}\right)\left(\frac{I_{1, t+1}(i)}{I_{1, t}(i)}\right)^{2}\right]=1 .
\end{gathered}
$$

$U_{C_{1, t}}(i)$ and $U_{N_{1, t}}(i)$ are the Ricardian household's marginal utilities of consumption and labor in period $t$, respectively

$$
U_{C_{1, t}}(i)=\exp \left(v_{t}^{d}\right)(1-\rho)\left(C_{1, t}(i)-\chi C_{1, t-1}\right)^{(1-\rho)\left(1-\sigma_{c}\right)-1}\left(1-N_{1, t}(i)\right)^{\rho\left(1-\sigma_{c}\right)}
$$


and

$$
U_{N_{1, t}}(i)=-\exp \left(v_{t}^{d}\right) \rho\left(C_{1, t}(i)-\chi C_{1, t-1}\right)^{(1-\rho)\left(1-\sigma_{c}\right)}\left(1-N_{1, t}(i)\right)^{\rho\left(1-\sigma_{c}\right)-1} .
$$

$Q_{1, t}(i)$ is the Tobin's $\mathrm{Q}$, defined as the ratio of the Lagrange multipliers over the capital accumulation equation and over the budget constraint,

$$
Q_{1, t}(i)=\frac{\mu_{1, t}(i)}{\lambda_{1, t}(i)}
$$

\subsubsection{Liquidity-Constrained Households}

\section{Preferences}

Non-Ricardian households, indexed by $h \in[1-\lambda, 1]$, do not face an external consumption habit, which sustains the fact that liquidity-constrained households do not bother to "catch up with the Joneses", nor a consumption preference shock, in the sense that they are not exposed to fashion trends. Unlike Ricardian consumers, their preferences are separable in consumption and leisure:

$$
U\left(C_{2, t}(b), N_{2, t}(b)\right)=\frac{C_{2, t}(h)^{1-\varsigma}}{1-\varsigma}-\frac{N_{2, t}(h)^{1+\varphi}}{1+\varphi}
$$

where $\varsigma$ is the inverse of the intertemporal elasticity of substitution and $\varphi$ the inverse of the Frisch elasticity.

\section{Budget Constraint}

A non-Ricardian household only receives wage income, which it spends on consumption goods:

$$
P_{t} C_{2, t}(h) \leq W_{t} N_{2, t}(h)
$$

\section{Optimality Conditions}

The liquidity-constrained household's optimal decision rules are characterized by the labor supply equation, which must satisfy:

$$
N_{2, t}(b)^{\varphi} C_{2, t}(h)^{\varsigma}=\frac{W_{t}}{P_{t}}
$$


and by the binding (real) budget constraint,

$$
C_{2, t}(h)=\frac{W_{t}}{P_{t}} N_{2, t}(b) .
$$

\subsection{Firms}

There are two types of firms in this economy: final goods firms and intermediate goods firms. Acting in a perfectly competitive market, retail firms buy differentiated intermediate goods $Y_{t}(j)$ from monopolistically competitive wholesale firms, which they combine to supply the economy with a single final good $Y_{t}$.

\subsubsection{Final Goods Sector: Retail Firms}

Dixit-Stiglitz Aggregate Demand and Prices

Final goods firms use differentiated intermediate goods as input to produce $Y_{t}$ according to:

$$
Y_{t}=\left(\int_{0}^{1} Y_{t}(j)^{\frac{\zeta-1}{\zeta}} d j\right)^{\frac{\zeta}{\zeta-1}},
$$

where $\zeta$ is the elasticity of substitution between intermediate goods. Retail firms choose $Y_{t}(j)$ at price $P_{t}(j)$ to minimize their total cost of production

$$
\int_{0}^{1} P_{t}(j) Y_{t}(j) d j
$$

subject to the constant returns technology function (13). The first-order condition yields a set of aggregate demands for each differentiated good $j$ as a function of their relative price $P_{t}(j)$ in terms of the aggregate price index $P_{t}$ :

$$
Y_{t}(j)=\left(\frac{P_{t}(\mathrm{j})}{P_{t}}\right)^{-\zeta} Y_{t},
$$

where $Y_{t}$ and $P_{t}$ are the Dixit and Stiglitz (1977) aggregates. From the zeroprofit condition, the aggregate price index can be written in terms of the price of differentiated goods as: 


$$
P_{t}=\left(\int_{0}^{1} P_{t}(j)^{1-\zeta} d j\right)^{\frac{1}{1-\zeta}}
$$

\subsubsection{Intermediate Goods Sector: Wholesale Firms}

\section{Production Technology}

There is a continuum of monopolistically competitive firms, indexed by $j \in(0,1)$, each producing a single differentiated good using labor and capital as inputs. Wholesale firms technology is represented by a standard Cobb-Douglas production function with a labor-augmenting productivity shock:

$$
Y_{t}(j)=\max \left\{\left[\exp \left(v_{t}^{a}\right) N_{t}(j)\right]^{\alpha} K_{t}(j)^{1-\alpha}, 0\right\}
$$

where $Y_{t}(j)$ denotes the differentiated output of the wholesale firm, $N_{t}(j)$ the hours of labor demanded and $K_{t}(j)$ the demand for capital. $v_{t}^{a}$ is a labor-augmenting productivity shock, common to all intermediate goods producers, following an AR(1) process $v_{t}^{a}=\rho_{a} v_{t-1}^{a}+\varepsilon_{t}^{a}$, with $\varepsilon_{t}^{a} \sim \mathrm{N}\left(0, \sigma_{a}^{2}\right)$.

\section{Factor Demands}

Wholesale firms solve a two-stage problem. In the first stage, they solve their cost minimization problem by optimally choosing the quantity of labor and capital they need (from perfectly competitive factor markets). The first-order conditions yield the relative factor demand:

$$
\frac{K_{t}(j)}{N_{t}(j)}=\frac{1-\alpha}{\alpha} \frac{W_{t} P_{t}}{R_{t}}
$$

and the real marginal cost

$$
M C_{t}=\exp \left(v_{t}^{a}\right)^{-\alpha} \alpha^{-\alpha}(1-\alpha)^{-(1-\alpha)}\left(\frac{W_{t}}{P_{t}}\right)^{\alpha} R_{t}^{(1-\alpha)}
$$

Note that the marginal cost does not depend on firm $j$ and therefore firms are effectively subject to the same technology shock. 


\section{Pricing Decision}

In the second stage, firms choose the price $P_{t}(j)$ that maximizes their expected sum of discounted profits in a Calvo (1983)-style staggered price setting with indexation. They are allowed to reoptimize prices with probability $(1-\xi)$ every period. In this case, $P_{t}^{0}(j)$ denotes the optimal price all firms would set if they were allowed to adjust it. Note that $(1-\xi)$ also represents the fraction of firms able to reset their prices and $1 /(1-\xi)$ the average duration for which prices are left unchanged. With probability $\xi$ a firm does not receive the permission to adjust its price but it is allowed to partially index it to lagged inflation according to

$$
P_{t}(j)=\prod_{t-1}^{\gamma} P_{t-1}(j)
$$

where $\gamma \in[0,1]$ is the degree of price indexation to lagged inflation. Firms allowed to reset prices in period $t$ maximize the discounted sum of expected nominal profits subject to the Dixit-Stiglitz production technology (13):

$$
\max _{P_{t}(j)} \mathbb{E}_{t} \sum_{s=0}^{\infty} \xi^{s} D_{t, t+s}\left(\prod_{\tau=1}^{s} \Pi_{t+\tau-1}^{\gamma} P_{t}(j)-P_{t+s} M C_{t+s} \exp \left(v_{t+s}^{p}\right)\right) Y_{t+s}(j),
$$

where $D_{t, t+s} \equiv \beta^{s}\left(\lambda_{1, t+s} / \lambda_{1, t}\right)$ is the stochastic discount factor (which assumes the same valuation as Ricardian households, where $\lambda_{1, t}$ is the Lagrange multiplier on their budget constraint) over the interval $[t, t+s], M C_{t}$ and $P_{t}$ are the real marginal cost and the aggregate price index in period $t$, respectively. $v_{t}^{p}$ is a price mark-up shock, common to all intermediate goods producers, described by $v_{t}^{p}=\rho_{p} v_{t-1}^{p}+\varepsilon_{t}^{p}$, with $\varepsilon_{t}^{p} \sim \mathrm{N}\left(0, \sigma_{p}^{2}\right)$.

The optimal price-setting first-order condition for a firm $j$ choosing the optimal price $P_{t}^{0}(j)$ in period $t$ is then given by:

$$
\begin{aligned}
\mathbb{E}_{t} \sum_{s=0}^{\infty} \xi^{s} D_{t, t+s} & {\left[\left(\prod_{\tau=1}^{s} \frac{\Pi_{t+\tau-1}^{\gamma}}{\prod_{t+\tau}}\right)^{1-\zeta}\left(\frac{P_{t}^{0}(j)}{P_{t}}\right)\right.} \\
& \left.-\frac{\zeta}{\zeta-1}\left(\prod_{\tau=1}^{s} \frac{\Pi_{t+\tau-1}^{\gamma}}{\Pi_{t+\tau}}\right)^{-\zeta} M C_{t+s} \exp \left(v_{t+s}^{p}\right)\right] Y_{t+s}=0,
\end{aligned}
$$


where the optimal price is found by weighting marginal profits by sales in different periods. If prices were fully flexible $(\xi=0)$, the price charged by firm $j$ would be a mark-up over real marginal costs $P_{t}^{0}(j)=\frac{\zeta}{\zeta-1} P_{t} M C_{t} \exp \left(v_{t}^{p}\right)$, where $\zeta$ is the price elasticity of demand. On the other hand, if $\xi=1$, the firm would charge constant prices. Finally, the evolution of the price index is determined by:

$$
P_{t}^{1-\zeta}=\xi\left(\Pi_{t-1}^{\gamma}\right)^{1-\zeta} P_{t-1}^{1-\zeta}+(1-\xi)\left(P_{t}^{0}\right)^{1-\zeta} .
$$

\section{New Keynesian Phillips Curve}

Combining the optimal pricing decision of the firm with the law of motion for aggregate prices, we obtain the log-linearized New Keynesian Phillips curve which introduces forward-looking expectations. Hence, current inflation is related to current real marginal costs and the price mark-up shock, lagged inflation and the expected future inflation rate:

$$
\pi_{t}=\mu_{m}\left(m c_{t}+v_{t}^{p}\right)+\mu_{f} \mathbb{E}_{t} \pi_{t+1}+\mu_{b} \pi_{t-1}
$$

where

$$
\mu_{m}=\frac{(1-\xi)(1-\beta \xi)}{\xi(1+\beta \gamma)}, \mu_{f}=\frac{\beta}{1+\beta \gamma}, \text { and } \mu_{b}=\frac{\gamma}{1+\beta \gamma} .
$$

Note that introducing indexation leads inflation to be persistent. Rewriting the equation in first differences and iterating it forwards, we find that the variation in the current inflation rate is solely determined by current and future expected marginal costs and price mark-up shocks:

$$
\pi_{t}-\gamma \pi_{t-1}=\frac{(1-\xi)(1-\beta \xi)}{\xi}\left(m c_{t}+v_{t}^{p}\right)+\beta\left(\mathbb{E}_{t} \pi_{t+1}-\gamma \pi_{t}\right)
$$

which can be rewritten as:

$$
\pi_{t}-\gamma \pi_{t-1}=\mu_{m}(1+\beta \gamma) \mathbb{E}_{t} \sum_{s=0}^{\infty} \beta^{s}\left(m c_{t+s}+v_{t}^{p}\right)
$$

As before, if prices were flexible, $\xi \rightarrow 0$, then $\mu_{m} \rightarrow \infty$ and variations in the real marginal cost would have a one-for-one impact on the first difference of 
the inflation rate. Moreover, if $\xi \rightarrow 1$, then $\mu_{m} \rightarrow 0$ and the Phillips curve would become horizontal since the first difference of the inflation rate would tend to zero.

\subsection{Fiscal Policy}

Government expenditures are financed through lump-sum taxes on Ricardian consumers and the budget is assumed to balance every period. Hence, in nominal terms we have:

$$
P_{t} G_{t}=(1-\lambda) P_{t} T_{1, t} \text {. }
$$

Furthermore, government spending in log-deviations from the steady-state evolves exogenously according to:

$$
g_{t}=\rho_{g} g_{t-1}+\varepsilon_{t}^{g},
$$

with $\varepsilon_{t}^{g} \sim \mathrm{N}\left(0, \sigma_{g}^{2}\right)$.

\subsection{Monetary Policy}

In this closed-economy setup, I assume monetary policy to be controlled by a central bank that sets the nominal interest rate according to a Taylor-type rule and whose reaction function responds optimally to the shocks of the model economy. The linearized version reads:

$$
\log \left(\frac{R_{n, t}}{R_{n}}\right)=\rho_{r} \log \left(\frac{R_{n, t-1}}{R_{n}}\right)+\left(1-\rho_{r}\right)\left(\theta_{\pi} \log \left(\frac{\Pi_{t}}{\Pi}\right)+\theta_{y} \log \left(\frac{Y_{t}}{\bar{Y}}\right)\right)+\varepsilon_{t}^{r},
$$

or

$$
r_{n, t}=\rho_{r} r_{n, t-1}+\left(1-\rho_{r}\right)\left(\theta_{\pi} \pi_{t}+\theta_{y} y_{t}^{g a p}\right)+\varepsilon_{t}^{r},
$$

where $r_{n, t}$ denotes the nominal interest rate and $y_{t}^{g a p}$ the output gap ${ }^{7} . R_{n}$ and $\Pi$ are the steady-state values of the nominal interest rate and inflation, respectively,

$7 y_{t}^{g a p}$ was first computed as the log-deviation from the flexible-price output as in SMETs and Wouters (2003). However, for the initial calibration the solution was locally indeterminate as suggested in Galí, LópeZ-SALIdo, and VALLÉs (2004) who report that an interest rate rule satisfying the Taylor principle is not sufficient to ensure the existence of a unique equilibrium. 
and $\bar{Y}_{t}$ represents the output long-term trend. $\varepsilon_{t}^{r}$ is an exogenous and non-systematic monetary policy shock defined as $\varepsilon_{t}^{r} \sim \mathrm{N}\left(0, \sigma_{r}^{2}\right)$.

\subsection{Shocks}

The model incorporates six exogenous stochastic disturbances ${ }^{8}$, independent and identically distributed among them, namely: on the Ricardian household's consumption behavior, $\varepsilon_{t}^{d}$, and investment decision, $\varepsilon_{t}^{i}$; on the intermediate goods firms production technology, $\varepsilon_{t}^{a}$, and pricing strategy, $\varepsilon_{t}^{p}$; on the government's expenditure pattern, $\varepsilon_{t}^{g}$; and on the monetary authority Taylor-type rule, $\varepsilon_{t}^{r}$.

\subsection{Market Clearing}

Goods market clearing requires the aggregate output to be equal to aggregate demand, i.e. to the sum of Ricardian and non-Ricardian households private consumption, investment and of government expenditure:

$$
Y_{t}=C_{t}+I_{t}+G_{t}
$$

where

$$
I_{t}=\int_{0}^{1-\lambda} I_{1, t}(i) d i
$$

The labor market is in equilibrium when the labor demanded by intermediate goods firms is satisfied by the labor supplied by Ricardian and non-Ricardian households at the market wage rate:

$$
\int_{0}^{1-\lambda} N_{1, t}(i) d i+\int_{1-\lambda}^{1} N_{2, t}(h) d h=\int_{0}^{1} N_{t}(j) d j \equiv N_{t} .
$$

The market clearing condition for capital is satisfied when Ricardian consumers supply of capital equals the demand for capital by wholesale firms at the market rental rate:

8 Note that to avoid stochastic singularity when evaluating the likelihood function, Dynare requires at least as many shocks or measurement errors as observable variables such that the covariance matrix of endogenous variables is non-singular. 


$$
\int_{0}^{1-\lambda} K_{1, t}(i) d i=\int_{0}^{1} K_{t}(j) d j \equiv K_{t} .
$$

Furthermore, note that in a symmetric equilibrium all intermediate goods producers set the same price. Therefore, the aggregate price index is equal to the intermediate goods price, $P_{t}=P_{t}(j)$, and the aggregate output equals the intermediate goods firms output, $Y_{t}=Y_{t}(j)$, for all $j$.

\section{Estimating the Model for Portugal: Data, Calibration, and Priors}

The linear rational expectations solution of the model is estimated using Bayesian maximum likelihood. ${ }^{9}$ From calibration to the Generalized Method of Moments, Classical to Bayesian maximum likelihood, several methods have been employed to estimate DSGE models. Introduced in the estimation of DSGE models by Dejong, Ingram, and Whiteman (2000), Schorfheide (2000), and Otrok (2001), Bayesian estimation has been widely used in the recent literature given its advantages in estimating rational expectation models. It allows the use of prior information to identify key structural parameters, to compare nested models, and can avoid the posterior distribution to peak in strange regions of the parameter space from, for example, a misspecified model (known as the "dilemma of absurd parameter estimates"). Bayesian estimation and model comparison are still consistent when the model is misspecified (Fernández-Villaverde and Rubio-Ramírez, 2004).

9 Bayesian methods are used to estimate the model's parameters by combining prior information and assumptions about parameters with information extracted from data - the likelihood function. One obtains the posterior kernel - a function proportional to the posterior density function. Monte Carlo Markov Chain simulation methods and sampling algorithms like Metropolis-Hastings or Gibbs (the former is the most used in the literature) provide the numerical background to compute posterior probability density distributions (GEwEKE, 1999). DeJong and Dave (2007), Canova (2007), and An and Schorfheide (2007) provide a comprehensive analysis on Bayesian macroeconometric methods used in the estimation of these models. Appendix B presents a summary explanation of the method followed throughout the paper. 


\section{Data}

The model is estimated using quarterly data covering the period 1995Q1 through 2012Q1 for real GDP, GDP deflator and the short-term nominal interest rate. Portuguese data was taken from the OECD in June 2012. Note that in the model state space, output is measured in deviations from a constant steady-state. Hence, as in SMETS and Wouters (2007), I took the log first difference of real GDP and of the GDP price deflator times 100. The nominal interest rate is taken as it is, in percentage terms and expressed in quarters. ${ }^{10}$ All series are seasonally adjusted.

Measurement equations for the observable variables and their model's counterparts are given by:

$$
\left[\begin{array}{l}
\text { Real GDP growth }_{t} \\
\text { Inflation }_{t} \\
\text { Nominal interest rate }_{t}
\end{array}\right]=\left[\begin{array}{l}
\log \left(\frac{Y_{t}}{\bar{Y}_{t}}\right)-\log \left(\frac{Y_{t-1}}{\bar{Y}_{t-1}}\right)+\text { trend growth } \\
\log \left(\frac{\Pi_{t}}{\Pi}\right)+\text { constant }_{\Pi} \\
\log \left(\frac{R_{n, t}}{R_{n}}\right)+\text { constant }_{R_{n}}
\end{array}\right],
$$

where the trend growth is given by $\log \left(\bar{Y}_{t}\right)-\log \left(\bar{Y}_{t-1}\right)$. For inflation and the interest rate, measurement errors are given by constant ${ }_{\Pi}$ and constant $R_{R_{n}}$, respectively. $\bar{Y}_{t}, \Pi$ and $R_{n}$ were defined above.

\section{Calibration}

Four parameters are fixed ex-ante and throughout the estimation procedure: the Ricardian households discount factor $\beta$ and preference parameter over consumption and leisure $\rho$; the rate of capital depreciation $\delta$ and the steady-state government spending-to-output ratio, $g_{y}=\mathrm{G} / Y$. The discount factor is set to 0.99 , which corresponds to a steady-state real gross interest rate of $4 \%$ per annum. From the equilibrium labor supply equation of Ricardian households in steady-state,

$$
\rho=\frac{1-N}{1+\left(\frac{c_{y}(1-\chi)}{\alpha}-1\right) N},
$$

10 It corresponds to the three month interbank rate for Portugal prior from joining the euro and thereafter to the European Interbank Offered Rate. 
and imposing the steady-state aggregate level of hours worked, $N$, to correspond to 10 hours spent at work per day (i.e., circa $42 \%$ of the households' time is spent supplying labor to firms), $\rho$ can be calibrated to 0.833. $c_{y}=\mathrm{C} / Y$, the aggregate consumption-to-output ratio, is found by solving $c_{y}=1-i_{y}-g_{y}$ from the aggregate resource constraint. ${ }^{11}$ As in Almeida (2009), $g_{y}$ is set to 0.14 and steady-state investment-to-output ratio, $i_{y}$, is found by using the labor income share in total output, $\alpha$, the rate of capital depreciation and the steady-state real interest rate:

$$
i_{y}=\frac{(1-\alpha) \delta}{R} .
$$

$\delta$ is 0.025 per quarter, which corresponds to a $10 \%$ annual depreciation rate, and $\alpha$ represents $70.5 \%$ of total output to ensure an investment-output ratio close to observed data $\left(i_{y}=0.21\right.$. $)$ The quarterly constant and non-cyclical term of the interest rate is set to zero such that the model variable is well mapped by the data.

Table 1: Calibrated Parameters and Implied Steady-State Values

\begin{tabular}{lc}
\hline Parameters & Value \\
\hline \multicolumn{3}{c}{ Calibrated } & parameters \\
$\beta$ & 0.99 \\
$\rho$ & 0.833 \\
$\delta$ & 0.025 \\
$g_{y}$ & 0.14 \\
\hline & Implied steady-state \\
$N_{S S}$ & 0.42 \\
$c_{y}$ & 0.65 \\
$i_{y}$ & 0.21 \\
$R$ & 0.035 \\
$\lambda$ & 0.50 \\
\hline
\end{tabular}

\section{Priors}

The standard errors of the innovations are assumed to follow inverse gamma distributions with mean 0.1 and standard deviation 2, except for the government spending for which the mean is 0.5 and standard deviation 2.75 . These relatively

11 The steady-state consumption and hours worked are assumed to be the same among both types of households so that, for a steady-state share of liquidity-constrained households of one half, they are equal to their aggregate counterparts. 
loose and harmonized priors account for the fact that the data is often very informative about the standard deviation of shocks. The persistence parameters of shock processes are assumed to follow a beta distribution with mean 0.6 and standard deviation 0.2 . The quarterly trend growth is assumed to be normally distributed around 0.25 with standard deviation 0.1 . The quarterly steady-state inflation non-cyclical component is gamma distributed with prior mean 0.625 and standard deviation 0.1 .

Concerning the utility functions, Ricardian and non-Ricardian households intertemporal elasticities of substitution are normally distributed with mean 1.5 and 1.25 , and standard deviations 0.375 and 0.35 , respectively. The inverse of the Frisch elasticity of non-Ricardian households follows a normal distribution centered on 2 with standard deviation 0.75 . Ricardian households habit persistence parameter follows a beta distribution with prior mean 0.7 and standard deviation 0.1 . The investment adjustment cost parameter is normally distributed with mean 2 and standard deviation 1.5.

The Calvo probability of price setting and indexation parameters are assumed to follow beta distributions centered around 0.75 and 0.5 respectively, suggesting prices are updated four times per year. Standard deviations are 0.1 for the former and 0.15 for the latter. The labor income share in total output follows a beta distribution, as well, with mean 0.7 and standard deviation 0.05 .

Regarding the Taylor rule describing the monetary policy, the persistence parameter is beta distributed with mean 0.75 and standard deviation 0.1 and the long-run coefficient on inflation and output gap are normally distributed. As noted in Galí, López-SALIdo, and Vallés (2004), to ensure local determinacy, the nominal interest rate response to a change in inflation must be significantly above unity. Hence, I consider the monetary authority to be tough nosed: the inflation response parameter is assumed to have prior mean 4.5 and the coefficient on output gap 0.825 . Standard deviations are 0.75 and 0.25 , respectively.

Regarding the fraction of non-Ricardian households, six specifications were tested:

- Specification a: In a first stage, $\lambda$ is estimated from a prior beta distribution with mean 0.5 and standard deviation 0.1 as in Coenen and Straub (2005). After initial estimations, the model proved to be indeterminate for values of $\lambda$ greater than 0.64 as reported in Section 4.1 below. Therefore, a truncated version of the beta distribution with an upper bound was considered for the remainder of the paper;

- Specification b.1: $\lambda$ is fixed at 0 , so that the model does not incorporate ruleof-thumb consumers; 
- Specification b.2: $\lambda$ is fixed at 0.25 , so that $25 \%$ of consumers are non-Ricardian;

- Specification b.3: $\lambda$ is fixed at 0.5 , so that the model incorporates half of both types of consumers;

- Specification b.4: $\lambda$ is fixed at 0.75 , so that $75 \%$ of households are non-Ricardian;

- Specification 6.5: $\lambda$ is fixed at 1 , so that the model economy is represented by liquidity-constrained households.

Table 2: Prior Distributions

\begin{tabular}{|c|c|c|c|}
\hline Parameters & Distrib. & Mean & Std. dev. \\
\hline \multicolumn{4}{|c|}{ Households } \\
\hline$\lambda$ & Beta & 0.50 & 0.10 \\
\hline$\sigma_{c}$ & Normal & 1.50 & 0.375 \\
\hline$\chi$ & Beta & 0.70 & 0.10 \\
\hline$\varsigma$ & Normal & 1.25 & 0.35 \\
\hline$\varphi$ & Normal & 2.00 & 0.75 \\
\hline$\phi_{X}$ & Normal & 2.00 & 1.50 \\
\hline \multicolumn{4}{|c|}{ Firms } \\
\hline$\alpha$ & Beta & 0.70 & 0.05 \\
\hline$\xi$ & Beta & 0.75 & 0.10 \\
\hline$\gamma$ & Beta & 0.50 & 0.15 \\
\hline \multicolumn{4}{|c|}{ Taylor rule } \\
\hline$\rho_{r}$ & Beta & 0.75 & 0.10 \\
\hline$\theta_{\pi}$ & Normal & 4.50 & 0.25 \\
\hline$\theta_{y}^{n}$ & Normal & 0.825 & 0.05 \\
\hline \multicolumn{4}{|c|}{ Shocks } \\
\hline$\rho_{d}, \rho_{a}, \rho_{i}, \rho_{p}, \rho_{g}$ & Beta & 0.60 & 0.20 \\
\hline$\sigma_{d}, \sigma_{a}, \sigma_{i}, \sigma_{p}, \sigma_{r}$ & Inv. Gamma & 0.10 & 2.00 \\
\hline$\sigma_{g}$ & Inv. Gamma & 0.50 & 2.75 \\
\hline \multicolumn{4}{|c|}{ Measurement errors } \\
\hline trend growth & Normal & 0.25 & 0.10 \\
\hline constant $_{\Pi}$ & Gamma & 0.625 & 0.10 \\
\hline
\end{tabular}




\section{Results}

\subsection{Indeterminacy under $\lambda=0.75$ and $\lambda=1$}

Galí, López-Salido, and Vallés (2004) report that the introduction of ruleof-thumb consumers can alter the model's equilibrium dynamics even when the interest rate rule satisfies the Taylor principle. Furthermore, Galí, LópezSAlido, and VAllés (2007) argue that indeterminacy may be the result of a combination of a large weight of non-Ricardian households and a high degree of price stickiness.

The baseline price stickiness parameter $\xi$ is calibrated to 0.75 like in GaLí, López-SALIDO, and VALLÉs (2007) and ceteris paribus under the different specifications tested, the BlaNCHARD and KAHN (1980) conditions are not satisfied when $\lambda=0.75$ and $\lambda=1$. And therefore no stable solution is found for the interest rate and the model's equilibrium is indeterminate. The indeterminacy region in this model starts when the baseline proportion of liquidity-constrained households $\lambda>0.64$, a lower value than Galí, López-Salido, and Vallés (2007) reported for their model.

\subsection{Non-Ricardian Households Driving Posterior Distributions}

The parameters posterior distributions are presented in Tables 4 to 7 , where the mode, mean, standard deviations, and the corresponding 5 and 95 percentiles of the posterior distributions are included. The value of the marginal likelihood is reported for both the Laplace approximation around the posterior mode and the Modified Harmonic Mean Estimator. Figures 7 to 10 show the prior and posterior distributions depicted in gray and black, respectively, and the posterior mode in green. ${ }^{12}$

Table 3 below summarizes the means of the posterior distributions for the alternative specifications of $\lambda$. The first interesting result is regarding the estimated fraction of non-Ricardian households (specification a). The posterior mean of $\lambda$ is $57.8 \%$. This result is considerably higher than what Coenen and Straub (2005) and Forni, Monteforte, and Sessa (2009) found for the euro area (25-37\% and 34-37\%, respectively) but in line with the 50\% Campbell and Mankiw (1989) report for the pre-1990 in the United States. Also, when the nontruncated beta distribution is used as a prior, $\lambda$ assumes a slightly greater value (close to 0.6 ). The posterior appears to be highly driven by the prior distribution.

12 They are available as supplementary material related to this article on the website of the Swiss Journal of Economics and Statistics (http://www.sjes.ch). 
Regarding the parameters influencing households optimal decision rules, the posterior distribution of the inverse of the intertemporal elasticity of substitution of Ricardian households is very much influenced by the share of rule-of-thumb consumers. For the specifications of $\lambda$ estimated and $\lambda$ calibrated to 0.5 , the obtained estimates are relatively similar to SMETS and Wouters (2003) for the euro area. However, when $\lambda$ is set at 0 or 0.25 , values for $\sigma_{c}$ are much lower than what is found in the literature and, surprisingly, much lower than one. In the case of liquidity-constrained consumers, the inverse of the intertemporal elasticity of substitution and of the Frisch elasticity seem to be more influenced by the prior. However, note that the posterior mean when $\lambda$ is estimated slightly differs from the case of $\lambda$ calibrated to 0.5 . Considering the habit persistence of Ricardian households, the different specifications do not seem to influence the estimated values of $\lambda$. Although these values are lower than the one reported by AlmEIDA (2009) for Portugal, they match the findings of SMETs and Wouters (2003) well. The investment adjustment cost parameter is estimated to be around 4.5 for specifications $a$ and $b .3$ and around 3.3 for $\lambda$ calibrated to 0 and 0.25 . These values are higher than the assumed prior but are still considerably lower than the values reported, for example, in Adolfson et al. (2007) for the euro area.

Concerning the parameters on firms optimal behavior, the estimates of the Calvo price stickiness parameter differ greatly depending on the value of $\lambda$. In the model without liquidity-constrained households, the average duration of price contracts is approximately one year and relatively close to other studies. On the other hand, when the fraction of non-Ricardian households is calibrated to 0.5 or estimated, prices become less sticky and are reoptimized every quarter on average. This may be at odds with the reality of the Portuguese economy where prices do not point to such a high degree of flexibility. The estimated degree of indexation follows the main results of AdoLfson et al. (2007) who suggest that prices are weakly related to past inflation and that the Phillips curve is mostly forward-looking. However, these values appear relatively low for the case where $\lambda$ is calibrated to 0 or to 0.25 .

The estimates of the interest rate smoothing parameter from the central bank's Taylor rule are close to SMets and Wouters (2003) when no or $25 \%$ of liquidity-constrained households are assumed: posterior means are 0.95 and 0.922 , respectively. When a higher fraction of rule-of-thumb consumers is considered, the estimates of $\rho_{r}$ are lower but closer to SMets and Wouters (2007) for the US economy. The inflation response parameter appears to be more influenced by the though-nosed prior when these two specifications are considered. However, for $\lambda$ calibrated to 0 or to 0.25 , the estimates still point to a value around 4. On the other hand, the estimates of the output response parameter are very 
Table 3: Estimates under the Alternative Specifications of $\lambda$

\begin{tabular}{|c|c|c|c|c|c|c|}
\hline \multirow[t]{2}{*}{ Parameters } & \multicolumn{2}{|c|}{ Prior } & \multicolumn{4}{|c|}{ Posterior Mean } \\
\hline & Distrib. & Mean & $\lambda$ estimated & $\lambda=0$ & $\lambda=0.25$ & $\lambda=0.5$ \\
\hline \multicolumn{7}{|c|}{ Households } \\
\hline$\lambda$ & Beta & 0.50 & 0.578 & - & - & - \\
\hline$\sigma_{c}$ & Normal & 1.50 & 1.223 & 0.350 & 0.172 & 1.568 \\
\hline$\chi$ & Beta & 0.70 & 0.612 & 0.596 & 0.574 & 0.596 \\
\hline$\varsigma$ & Normal & 1.25 & 1.405 & - & 1.296 & 1.235 \\
\hline$\varphi$ & Normal & 2.00 & 1.870 & - & 1.994 & 1.999 \\
\hline$\phi_{X}$ & Normal & 2.00 & 4.585 & 3.510 & 3.128 & 4.482 \\
\hline \multicolumn{7}{|c|}{ Firms } \\
\hline$\alpha$ & Beta & 0.70 & 0.684 & 0.691 & 0.694 & 0.629 \\
\hline$\xi$ & Beta & 0.75 & 0.235 & 0.735 & 0.530 & 0.190 \\
\hline$\gamma$ & Beta & 0.50 & 0.336 & 0.181 & 0.234 & 0.365 \\
\hline \multicolumn{7}{|c|}{ Taylor rule } \\
\hline$\rho_{r}$ & Beta & 0.75 & 0.830 & 0.950 & 0.922 & 0.861 \\
\hline$\theta_{\pi}$ & Normal & 4.50 & 4.598 & 4.012 & 3.993 & 4.448 \\
\hline$\theta_{y}$ & Normal & 0.825 & 0.334 & 0.244 & 0.055 & 0.354 \\
\hline \multicolumn{7}{|c|}{ Shocks } \\
\hline$\rho_{d}$ & Beta & 0.60 & 0.948 & 0.843 & 0.873 & 0.955 \\
\hline$\rho_{a}$ & Beta & 0.60 & 0.695 & 0.741 & 0.971 & 0.688 \\
\hline$\rho_{i}$ & Beta & 0.60 & 0.606 & 0.603 & 0.597 & 0.601 \\
\hline$\rho_{p}$ & Beta & 0.60 & 0.781 & 0.598 & 0.606 & 0.758 \\
\hline$\rho_{g}$ & Beta & 0.60 & 0.699 & 0.597 & 0.595 & 0.694 \\
\hline$\sigma_{d}$ & Inv. Gam. & 0.10 & 1.259 & 3.346 & 1.952 & 1.494 \\
\hline$\sigma_{a}$ & Inv. Gam. & 0.10 & 0.055 & 8.070 & 3.598 & 0.056 \\
\hline$\sigma_{i}$ & Inv. Gam. & 0.10 & 0.090 & 0.081 & 0.081 & 0.084 \\
\hline$\sigma_{p}$ & Inv. Gam. & 0.10 & 4.378 & 0.119 & 0.081 & 4.515 \\
\hline$\sigma_{g}$ & Inv. Gam. & 0.50 & 0.277 & 0.445 & 0.461 & 0.276 \\
\hline$\sigma_{r}$ & Inv. Gam. & 0.10 & 0.367 & 0.137 & 0.167 & 0.291 \\
\hline \multicolumn{7}{|c|}{ Measurement errors } \\
\hline trend growth & Normal & 0.25 & 0.357 & 0.270 & 0.186 & 0.358 \\
\hline constant $_{\Pi}$ & Gamma & 0.625 & 0.691 & 0.705 & 0.717 & 0.691 \\
\hline
\end{tabular}


distinct from the assumed priors for any of the specifications tested. The posterior mean when $\lambda$ is 0.25 appears to be closer to values reported in the literature even for such a high prior mean. For the other specifications, $\theta_{y}$ is still considerably high, assuming a value of 0.24 for the model with only Ricardian households and values around 0.34 for the other cases.

Turning to the persistence of structural shocks, the estimates of the Ricardian households consumption preference shock are slightly distinct from the assumed priors. For the cases where $\lambda$ is calibrated to 0.5 or $\lambda$ is estimated, the shock is extremely persistent which could indicate the presence of a unit root. For the model considering no rule-of-thumb consumers, the posterior mean 0.843 follows the result of SMets and Wouters (2003), while for $\lambda$ calibrated to 0.25 the estimate is closer to Adolfson et al. (2007). The productivity shock appears to be highly persistent for the specification $b .2$. Instead, in the other cases, the persistence parameter is estimated to lie between 0.69 and 0.74 . Regarding the autoregressive parameter of the investment efficiency shock, the estimates are greatly influenced by the prior under any of the specifications considered and are relatively lower than what other papers reported. The same conclusion can be drawn in the cases of the price markup and government spending shocks when $\lambda$ is calibrated to 0 or to 0.25 , for which the posterior mean fluctuates around 0.6. $\lambda$ seems to influence their persistence when the fraction of rule-of-thumb consumers is estimated or calibrated to 0.5 .

The volatility of shocks is also strongly influenced by the level of $\lambda$. The consumption preference and technology shocks are the most volatile when the fraction of liquidity-constrained households is set to zero, whereas in the case of the price markup shock the process is highly volatile when $\lambda$ is estimated or calibrated to 0.5 . The estimates of the standard deviations of the investment, government spending and monetary policy shocks seem not to be significantly different under the alternative specifications of $\lambda$.

\section{Sensitivity to priors}

Tables 8 and 9 present the estimates of the mode by changing prior distributions of several parameters for the alternative specifications of $\lambda$. In a first attempt, the parameters prior distributions were readjusted relative to the benchmark model (10\% increase in means and standard deviations). Overall, the estimated modes have changed for most parameters but not substantially. Some exceptions are worth mentioning: when $\lambda$ is estimated or calibrated to 0.5 , the estimated modes of the investment adjustment cost parameter are well below their counterparts from the benchmark model; under specifications $a$ and $b .1$, the estimates of the inverse of the intertemporal elasticity of substitution of Ricardian households 
have increased with the change of priors. A higher value of the output response parameter from the Taylor rule is reported for $\lambda$ calibrated to 0.25 . Furthermore, for all specifications, persistence and standard deviations estimates are quite distinct from the posterior modes computed under the benchmark model.

In case 2, the prior mean of the investment adjustment cost parameter is set to 0.1 . As a result, its posterior mode is zero for any of the four different specifications of $\lambda$. Furthermore, the Calvo price stickiness decreases when $\lambda$ is calibrated to 0 or to 0.25 , being compensated by an increase in the price indexation. Under these specifications, the Taylor rule output response also increases. In case 3, the Calvo price stickiness prior mean is set to 0.1 . For the different specifications of $\lambda$, the Calvo pricing probability is nearly 0 and the price indexation estimates fluctuates above 0.5 . Surprisingly, the estimates of the investment adjustment cost parameter are 0 for $\lambda$ calibrated to 0 or 0.25 but fluctuates around 2, the prior mean, when $\lambda$ is estimated or calibrated to 0.5 . The obtained estimates of the standard deviations of shocks are slightly lower than the results found in the benchmark model. Although these results indicate some sensibility to priors for certain parameters, the qualitative results are quite satisfactory. 


\subsection{Impulse Response to Shocks Differs Depending on $\lambda$}

Further light is shed on the effect of the alternative specifications of the share of non-Ricardian households by analyzing dynamic responses of output growth, inflation and the nominal interest rate to a one standard deviation shock.

\section{The Effect of a Consumption Preference Shock}

Figure 1 presents the IRFs to a Ricardian households consumption preference shock. As revealed in the upper left panel, output responses are more pronounced in the case where $\lambda$ calibrated to 0 or to 0.25 . In any of the alternatives, output growth returns to the steady-state value after seven quarters. The upper right panel presents a very similar positive response of inflation. In the lower left panel, the bell-shaped response of the interest rate disappears in the case where $\lambda$ is estimated or calibrated to 0.5 . Also, the shock is persistent under all specifications.

Figure 1: Orthogonalised IRFs to a Consumption Preference Shock
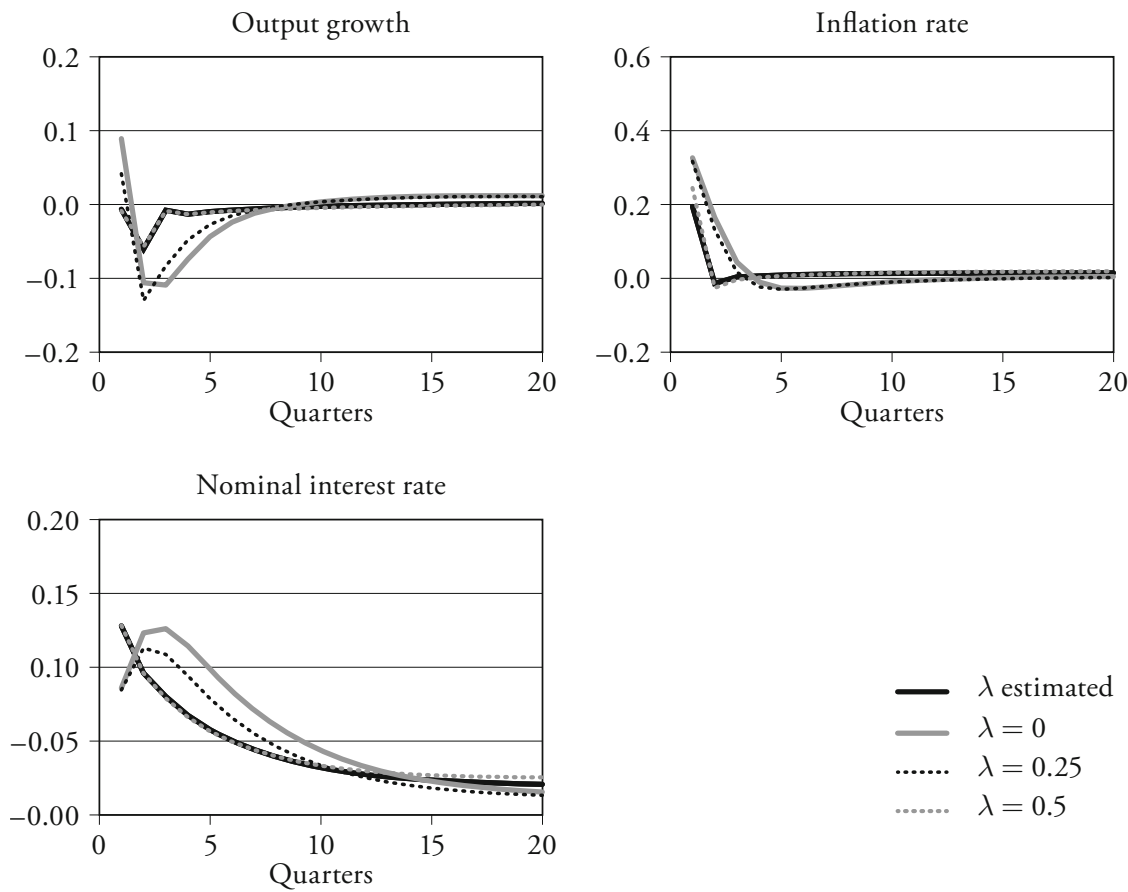


\section{The Effect of a Productivity Shock}

Figure 2 depicts the IRFs to a labor-augmenting productivity shock. In the case where $\lambda$ is estimated or calibrated to 0.5 , output growth, inflation and interest rate responses are negligible. Under the other specifications, the positive response of output growth to the shock is extremely high. Inflation and the interest rate respond negatively to the shock but when $\lambda$ is calibrated to 0 the readjustment to steady-state is more sluggish. Moreover, the model predicts that the nominal interest rate does not readjust to steady-state until at least 20 quarters after the shock.

Figure 2: Orthogonalized IRFs to a Productivity Shock
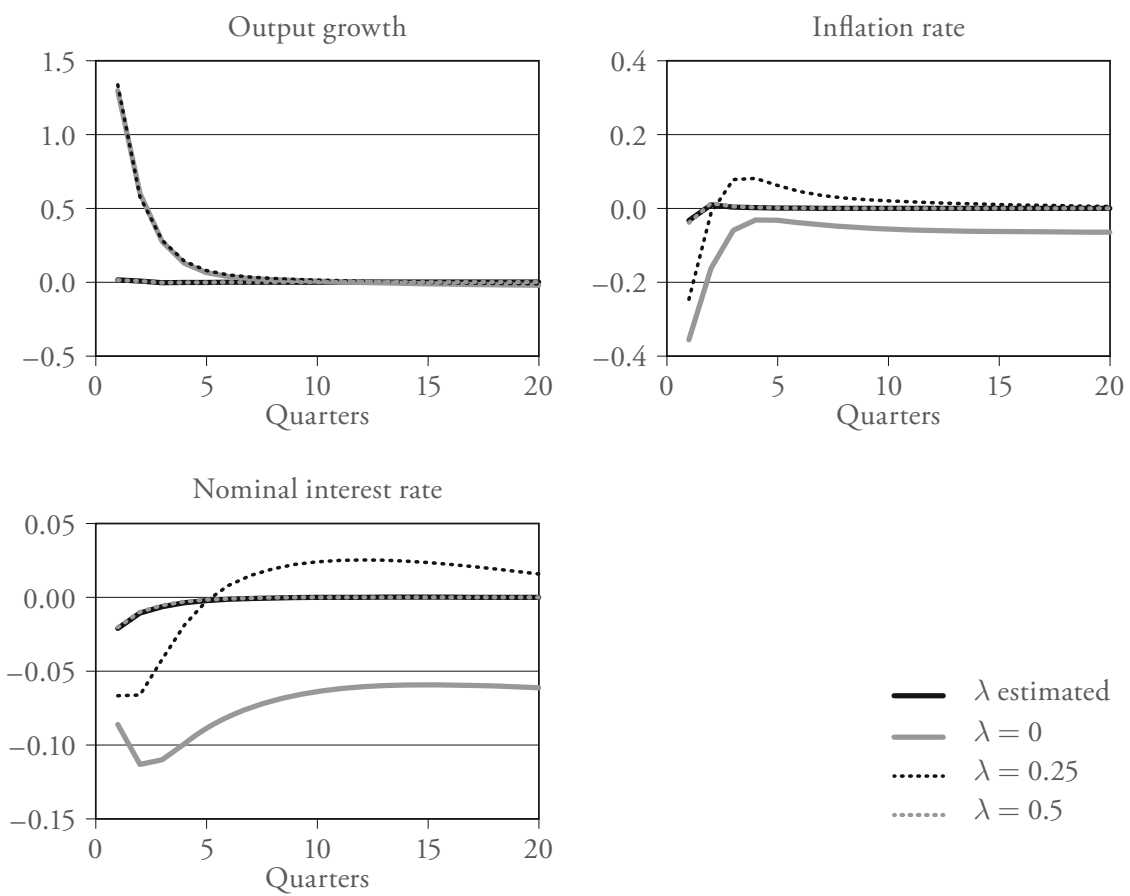


\section{The Effect of an Investment Efficiency Shock}

Figure 3 presents the IRFs to a Ricardian households investment efficiency shock. The effect of the shock on output growth and inflation are very similar under the different specifications of $\lambda$. However, the interest rate response when $\lambda$ is estimated or calibrated to 0.5 is more pronounced than in the other cases. Note that the magnitude of the shock is extremely high for all variables.

Figure 3: Orthogonalized IRFs to an Investment Efficiency Shock
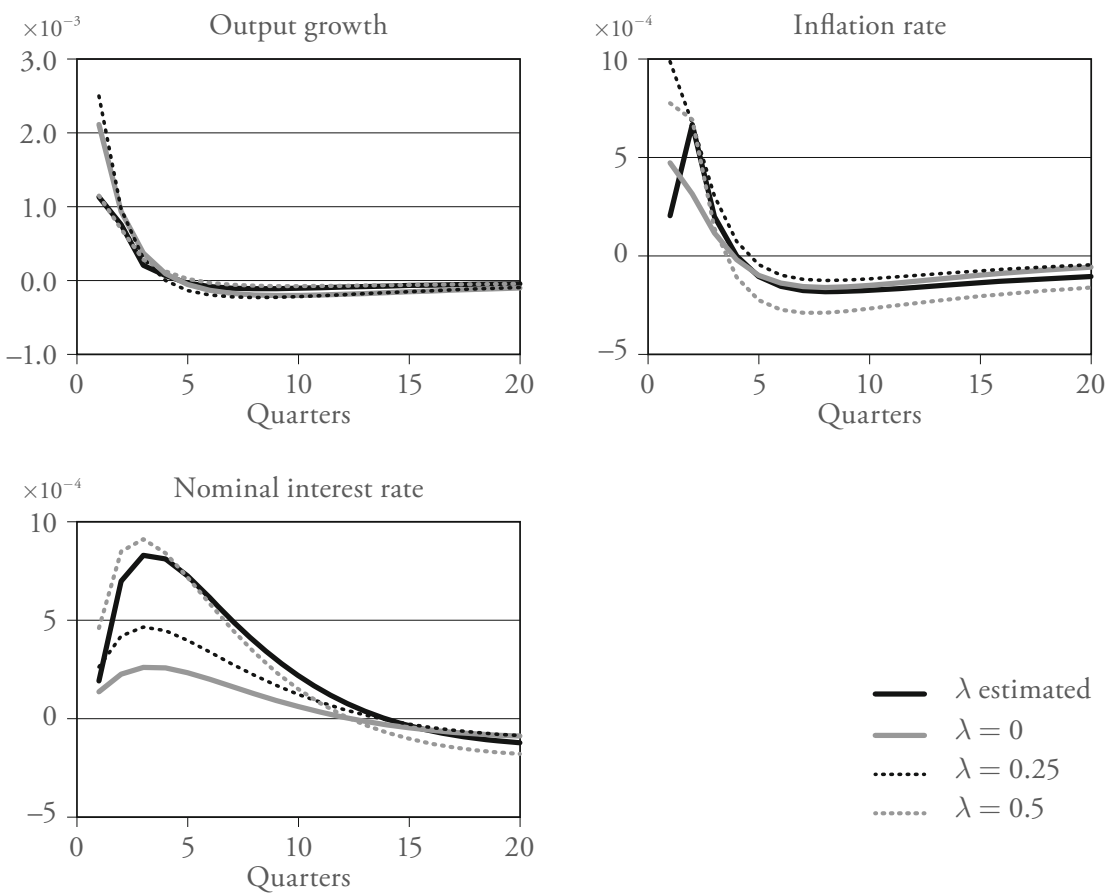


\section{The Effect of a Price Markup Shock}

The model predicts a very insignificant response of output growth, inflation and the interest rate when $\lambda$ is calibrated to 0 or 0.25 , as shown in Figure 4. Under the other specifications, a steep decrease of output growth is predicted after a price markup shock, returning to steady-state after ten quarters. The impact multipliers in inflation and the interest rate are considerably small.

Figure 4: Orthogonalized IRFs to a Price Markup Shock
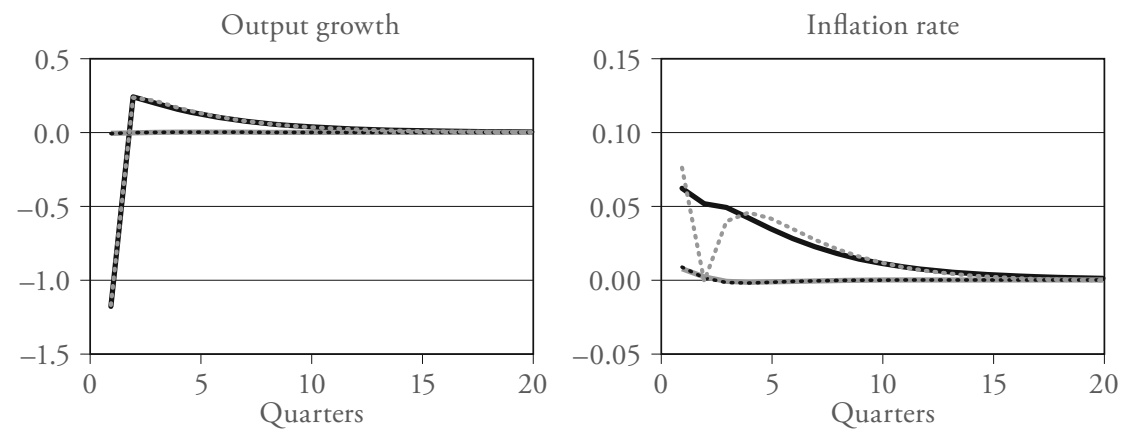

Nominal interest rate

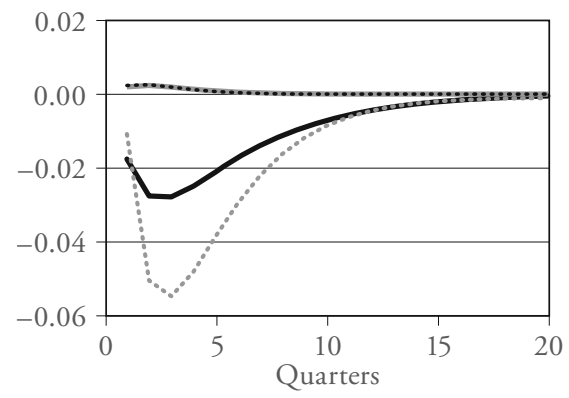

- $\lambda$ estimated

$\lambda=0$

…... $\lambda=0.25$

$\ldots \lambda=0.5$ 


\section{The Effect of a Government Spending Shock}

The government spending shock has a very slight impact on output growth, inflation and the interest rate in magnitude, as shown in Figure 5. A more pronounced response of inflation and the interest rate can be perceived when $\lambda$ is estimated or calibrated to 0.5 but for both cases the impact multiplier is below 0.04 .

Figure 5: Orthogonalized IRFs to a Government Spending Shock

Output growth

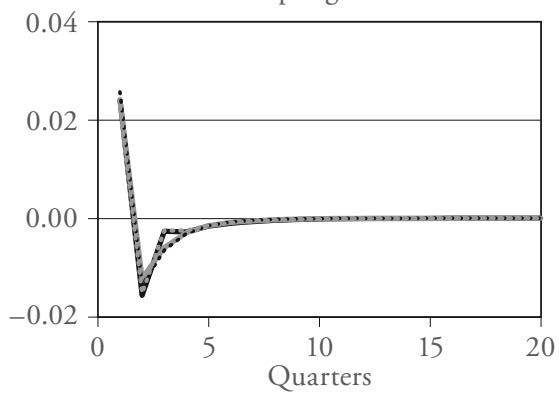

Nominal interest rate

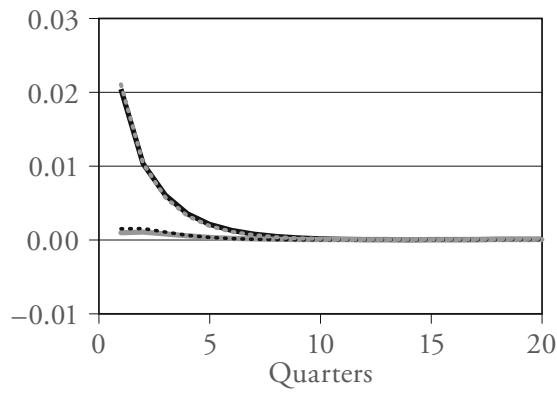

Inflation rate

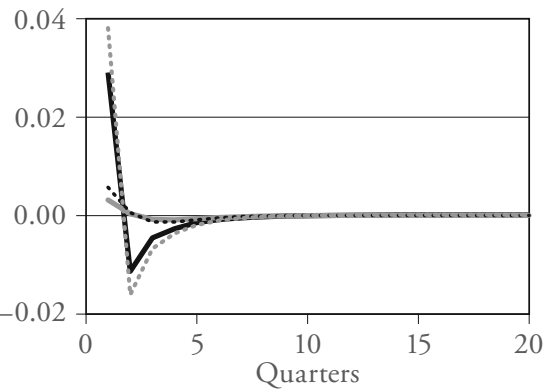

$\longrightarrow \lambda$ estimated $\lambda=0$

…... $\lambda=0.25$

..... $\lambda=0.5$ 


\section{The Effect of a Monetary Policy Shock}

The output growth and inflation responses are very similar for different levels of $\lambda$. However, in the lower left panel of Figure 6, the model predicts opposite scenarios: when $\lambda$ is calibrated to 0 or 0.25 , the nominal interest rate responds positively to the shock; however, when $\lambda$ is estimated or calibrated to 0.5 , the effect of the shock is nearly insignificant but curiously there is still a small decrease upon the impact of the shock. This may indicate that the presence of liquidityconstrained consumers has an indirect influence on financial markets by making them bear the costs of the increase in the central bank's interest rate.

Figure 6: Orthogonalized IRFs to a Monetary Policy Shock
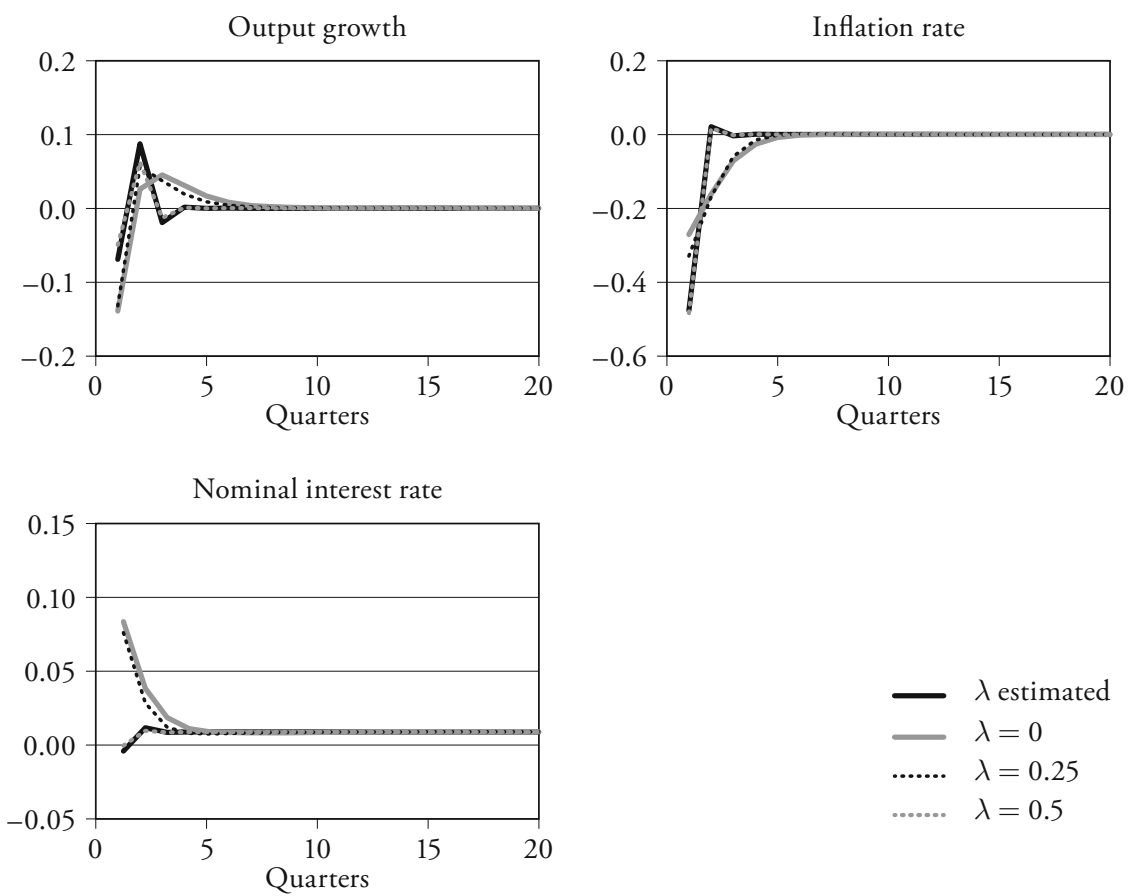


\subsection{Main Sources of Fluctuations in Endogenous Variables Conditional on $\lambda$}

\section{Variance Decomposition}

Tables 10 to 13 report the contribution of each structural shock to fluctuations in output growth, inflation and the nominal interest rate at different horizons: 1-4 quarters, defined as the short run; 10 quarters, the medium run; and 20 quarters, the long run. The forecast-error variance decomposition is computed at the posterior mode and conditional on period's $t$ information.

From the short to the long run, fluctuations in output drastically differ among the different specifications. When $\lambda$ is calibrated to 0 or 0.25 , the productivity shock accounts for more than $97 \%$ of the movements, whereas when $\lambda$ is estimated or calibrated to 0.5 most fluctuations are driven by the price markup shock (on average $98 \%$ ). Under specifications $a$ and $b .3$, developments in inflation are primarily driven by the monetary policy shock, accounting for more than $80 \%$ when $\lambda$ is estimated and around $75 \%$ when $\lambda$ is calibrated to 0.5 . The consumption preference shock gains some importance over the quarters accounting for $14 \%$ in specification $a$ and $20 \%$ in b.3. It is also one of the main drivers of variations in the inflation rate when $\lambda$ is calibrated to 0 and to $0.25: 35$ and $37 \%$ in the short run, respectively. The productivity shock explains great part of inflation movements under these specifications: from 41 in the first quarter to $46 \%$ in the long run; and from 23 to $24 \%$, respectively. Also, the contributions of monetary policy shocks are 25 and $40 \%$ under specifications b.1 and b.2.

The consumption preference shock seems to be the most relevant in explaining movements in the interest rate across the four different specifications. It accounts for more than $90 \%$ when $\lambda$ is estimated or calibrated to 0.5 . For $\lambda$ calibrated to 0.25 , it accounts for $42 \%$ in the short run and almost 73 in quarter 20 . When $\lambda$ is calibrated to 0 , the consumption preference shock accounts for $35 \%$ in quarter 1 and 42 in the long run, which together with the productivity shock account for more than $96 \%$ of the interest rate fluctuations in the long run. Furthermore, in the short run, the monetary policy shock accounts for $30 \%$ of the variations, either under specifications $b .1$ or b.2. Surprisingly, in any of the specifications, the investment-specific technology and the government spending shocks seem to be irrelevant in explaining output growth, inflation and interest rate developments. 


\section{Historical Decomposition}

Figures 11 to 22 show the historical contribution of each shock to output growth, inflation and the nominal interest rate over the sample period. ${ }^{13}$ While under specifications $a$ and $b .3$ cyclical peaks and troughs of output growth are mainly driven by price markup shocks, historical fluctuations when $\lambda$ is assumed to be 0 or 0.25 are driven by productivity shocks. The main sources of shifts in inflation over 1996 to 2011 are considered to be monetary policy and consumption preference shocks when $\lambda$ is estimated or calibrated to 0.5 . When $\lambda$ is calibrated to 0 or 0.25 , productivity shocks are another important source of inflation fluctuations. The variations in the interest rate are to a large extent explained by consumption preference shocks when $\lambda$ is estimated or calibrated to 0.5 . Price markup shocks played a relevant role, as well, from the early 2003s to 2008. Considering the model without rule-of-thumb consumers, productivity and consumption preference shocks account for most of the variations. Productivity shocks lose their importance in explaining interest rate fluctuations when $\lambda$ is calibrated to 0.25 .

\section{Conclusion}

In this paper, I have shown that the choice of the share of non-Ricardian households in a New Keynesian DSGE model, be it estimated or calibrated, is far from trivial. Different specifications lead to very different results. First and foremost, the proportion of rule-of-thumb consumers is estimated to be quite high (58\%), which is in line with Campbell and Mankiw (1989) for the pre-1990 in the US. This value may seem plausible for the Portuguese economy, where a significant part of the population is unable to save and therefore has no means to smooth consumption over time. Secondly, posterior distributions of structural parameters differ among the four alternative specifications of the share of liquidity-constrained households. In particular, for the following parameters: (i) the inverse of the intertemporal elasticity of substitution of Ricardian households; (ii) the investment adjustment cost parameter; (iii) the degree of price stickiness and the price indexation parameter; (iv) the output response coefficient from the central bank Taylor-type rule; and (v) the persistence and volatility of shocks are quite distinct under the alternative specifications of $\lambda$. In addition, when the fraction of liquidity-constrained households is calibrated to values greater than $64 \%$, the solution of the system of difference equations describing

13 They are available as supplementary material related to this article on the website of the Swiss Journal of Economics and Statistics (http://www.sjes.ch). 
the log-linearized model's equilibria is not unique. This result supports the findings of Galí, López-Salido, and Vallés (2004) and Galí, López-Salido, and VALLÉs (2007) who report that even if the Taylor principle is satisfied a combination of a high degree of price stickiness with a large weight of non-Ricardian households may render the interest rate rule locally indeterminate.

Ergo, responses to shocks also depend on the fraction of rule-of-thumb consumers. The model with no or $25 \%$ of liquidity-constrained households predicts a greater variation of output growth and a more persistent response of the shortterm nominal interest rate to a Ricardian households consumption preference shock. Responses to a productivity shock are almost nonexistent for high weights of non-Ricardian consumers, whereas an investment efficiency shock under these specifications causes a greater impact multiplier in the nominal interest rate response. The effect of a price markup shock on output growth and inflation is greater for higher values of $\lambda$.

Fluctuations in output growth, inflation and the nominal interest rate may be driven by different structural shocks depending on the fraction of rule-of-thumb consumers. For lower shares (0 or $25 \%$ ), fluctuations in output growth are mainly driven by productivity shocks, while fluctuations in inflation and the nominal interest rate are driven by consumption preference, productivity and monetary policy shocks. For higher values of $\lambda$, fluctuations in output growth are essentially driven by price markup shocks, while monetary policy shocks account for most of the variations in inflation, and consumption preference shocks drive short-term nominal interest rate movements.

Of course, some caveats must be mentioned. Primarily, the fiscal policy set up is rather simple, which translates into a relatively weak role for government intervention. Moreover, the closed-economy model should be made open in order to better describe data dynamics and to account for external shocks propagation. Finally, it will be interesting to explore the model performance using the DSGE-VAR approach suggested by Del Negro and Schorfheide (2004) and Del Negro et al. (2007) and to perform quantitative policy prediction in this Bayesian framework and assess the model's forecast performance. One could also extend the model to assume agents with cognitive limitations, who update their expectations like econometricians do by using a statistical forecasting rule (Evans and Honkapohja, 2001). As suggested by Milani (2007), it could be an alternative to rigidities and frictions assumed in the standard DSGE model. 


\section{Appendix}

\section{A Log-linearized equations}

Using a first-order Taylor expansion of the form $F\left(X_{t}, Y_{t}\right) \simeq F(X, Y)+F_{X}\left(X_{t}-X\right)$ $+F_{Y}\left(Y_{t}-Y\right)$, the model's equations are $\log$-linearized around the steady-state. This has a useful interpretation, variables are expressed as deviations from their long-run trend or their steady-state value if they do not have a trend ( $X$ and $Y$ above). Denoting $x_{t}=\log X_{t}-\log X$, we have:

\section{Ricardian Households Optimality Conditions}

Consumption Euler equation:

$$
u_{c_{1, t}}+q_{1, t}=\mathbb{E}_{t}\left[u_{c_{1, t+1}}+\beta\left(R r_{t+1}+(1-\delta) q_{1, t+1}\right)\right],
$$

where

$$
u_{c_{1, t}}=v_{t}^{d}+\left[(1-\rho)\left(1-\sigma_{c}\right)-1\right] \frac{C_{1}}{C_{1}(1-\chi)}\left(c_{1, t}-\chi c_{1, t-1}\right)-\rho\left(1-\sigma_{c}\right) \frac{N_{1}}{1-N_{1}} n_{1, t} .
$$

Labor supply equation:

$$
u_{n_{1, t}}-u_{c_{1, t}}=w_{t}-p_{t}
$$

where

$$
u_{n_{1, t}}=v_{t}^{d}+(1-\rho)\left(1-\sigma_{c}\right) \frac{C_{1}}{C_{1}(1-\chi)}\left(c_{1, t}-\chi c_{1, t-1}\right)-\left[\rho\left(1-\sigma_{c}\right)-1\right] \frac{N_{1}}{1-N_{1}} n_{1, t} .
$$

Investment decision equation:

$$
i_{1, t}(1+\beta)=i_{1, t-1}+\beta \mathbb{E}_{t} i_{1, t+1}+\frac{q_{1, t}+v_{t}^{i}}{S^{\prime \prime}(1)} .
$$

Capital accumulation equation:

$$
k_{1, t+1}=(1-\delta) k_{1, t}+\delta\left(i_{1, t}+v_{t}^{i}\right) .
$$


Non-Ricardian households optimality conditions

Consumption equation:

$$
c_{2, t}=w_{t}-p_{t}+n_{2, t}
$$

Labor supply equation:

$$
\varphi n_{2, t}+\zeta c_{2, t}=w_{t}-p_{t} .
$$

Intermediate goods firms first-order conditions

Aggregate output function:

$$
y_{t}=\alpha\left(v_{t}^{a}+n_{t}\right)+(1-\alpha) k_{t} .
$$

Capital-labor ratio:

$$
k_{t}-n_{t}=w_{t}-r_{t}
$$

Real marginal cost:

$$
m c_{t}=w_{t}-p_{t}+n_{t}-y_{t}
$$

Pricing decision:

$$
j_{t}-h_{t}=(1-\beta \xi)\left(m c_{t}+v_{t}^{p}\right)+\beta \xi \mathbb{E}_{t}\left(\pi_{t+1}-\gamma \pi_{t}+j_{t+1}-h_{t+1}\right) .
$$

The Law of Motion for Prices

New Keynesian Phillips curve

$$
\pi_{t}=\frac{(1-\xi)(1-\beta \xi)}{\xi(1+\beta \gamma)}\left(m c_{t}+v_{t}^{p}\right)+\frac{\beta}{1+\beta \gamma} \mathbb{E}_{t} \pi_{t+1}+\frac{\gamma}{1+\beta \gamma} \pi_{t-1} .
$$


The Real Government Balanced Budget Constraint

$$
g_{t}=\tau_{1, t}
$$

The Central Bank Taylor-Type Rule

$$
r_{n, t}=\rho_{r} r_{n, t-1}+\left(1-\rho_{r}\right)\left(\theta_{\pi} \pi_{t}+\theta_{y} y_{t}^{g a p}\right)+\varepsilon_{t}^{r} .
$$

The Fisher Equation

$$
r_{t}=r_{n, t}-\pi_{t}
$$

The Goods Market Clearing Condition

$$
\begin{aligned}
y_{t} & =\frac{C}{Y} c_{t}+\frac{I}{Y} i_{t}+\frac{G}{Y} g_{t} \\
c & =(1-\lambda) c_{1, t}+\lambda c_{2, t} \\
n_{t} & =(1-\lambda) n_{1, t}+\lambda n_{2, t} \\
k_{t} & =k_{1, t} \\
i_{t} & =i_{1, t} .
\end{aligned}
$$

\section{B Estimation Method}

\section{Likelihood Function}

The model is mapped to the data using a measurement equation of the form $y_{t}^{\text {data }}=C x_{t}+D u_{t}$, where $y_{t}^{\text {data }}$ denotes the vector of observable time series, $C$ is a matrix mapping the model's endogenous variables, $x_{t}$, to the observed data. $D$ is a matrix of coefficients and the vector of measurement errors $u_{t}$ follows a white noise process $u_{t} \sim N\left(0, \Sigma_{u}\right)$ and $\mathbb{E}\left(u_{t} u_{\tau}\right)=0$ for $t \neq \tau$. The log-likelihood function of $y_{t}^{\text {data }}$ conditional on the vector of parameters $\theta \in \Theta$ is then given by:

$$
\begin{aligned}
\mathcal{L}\left(y^{\text {data }} \mid \theta\right)= & -\frac{T n}{2} \ln 2 \pi-\frac{1}{2} \sum_{t=1}^{T} \ln \left|\Sigma_{y^{\text {data }}, t \mid t-1}\right| \\
& -\frac{1}{2} \sum_{t=1}^{T} e_{t \mid t-1}^{\prime} \Sigma_{y^{\text {data }}, t \mid t-1}^{-1} e_{t \mid t-1}
\end{aligned}
$$


where

$$
\sum y^{\text {data }}, t \mid t-1
$$

is a predictor of the variance-covariance matrix of the one-step-ahead forecast errors,

$$
e_{t \mid t-1}=y_{t}^{\text {data }}-y_{t \mid t-1}^{\text {data }}
$$

a vector of the one-step-ahead forecast errors from using parameters $\theta$ to predict sample variables $y_{t}^{\text {data }}$, and the number of observable variables is $n$. The log-likelihood is evaluated using the Kalman Filter.

\section{Prior Distributions}

The specification of a prior density $p(\theta)$ is central to the Bayesian estimation process. It represents the beliefs of the researcher on model parameters and an additional source of information in the computation of the posterior which can be independent from the data. Priors can be non-informative, or invariant to parametrization, when we want to minimize the prior's influence on the posterior. Classical Maximum likelihood estimators can be viewed as Bayesian estimators with uniform priors. Or on the other hand, priors can be informative and be a close representation of the data (predictive density of the data). The choice of appropriate priors lies normally between these two extrema.

In spite of each parameter's singularities: the beta distribution was used for fractions or probabilities; inverse gamma distribution for shocks' standard deviations, bounded to be positive; and the normal distribution for non-bounded parameters and when more informative priors seem necessary. Following SMETs and Wouters $(2007,2008)$, the gamma distribution, with support $[0, \infty)$, is used for the measurement error of the observable variable defining inflation. The definition of prior means and standard deviations is mainly based on empirical evidence from other papers and on their implications for macroeconomic dynamics. For the remaining cases, weakly informative priors with relatively large supports were considered.

\section{Posterior Computation}

The posterior distribution of the model's parameters, $p\left(\theta \mid y^{\text {data }}\right)$, is obtained by Bayes theorem:

$$
p\left(\theta \mid y^{\text {data }}\right)=\frac{L\left(y^{\text {data }} \mid \theta\right) p(\theta)}{\int_{\Theta} L\left(y^{\text {data }} \mid \theta\right) p(\theta) d \theta}
$$


where $L\left(y^{\text {data }} \mid \theta\right)$ is the likelihood function of the sample $y^{\text {data }} \in Y$ and $p(\theta)$ the prior density of the parameter vector $\theta$.

$$
\int_{\Theta} L\left(y^{\text {data }} \mid \theta\right) p(\theta) d \theta
$$

denotes the marginal sample density. Note that the marginal density of the data is a constant term. Therefore, the posterior density proportionally corresponds to the sample density multiplied by the prior density, or simply the posterior kernel:

$$
p\left(\theta \mid y^{\text {data }}\right) \propto L\left(y^{\text {data }} \mid \theta\right) p(\theta)=\mathcal{K}\left(\theta \mid y^{\text {data }}\right) .
$$

In logs, we have the log-posterior kernel expressed as:

$$
\log \mathcal{K}\left(\theta \mid y^{\text {data }}\right)=\mathcal{L}\left(y^{\text {data }} \mid \theta\right)+\log p(\theta),
$$

where $\mathcal{L}\left(y^{\text {data }} \mid \theta\right)$ is the log-likelihood function defined above. The mode of the posterior distribution, as well as the Hessian at this point, are estimated using Sim's algorithm csminwel, which maximizes (B.4) with respect to $\theta .^{14}$

\section{Markov Chain Monte Carlo (MCMC) Metropolis-Hastings (MH) Algorithm}

A closed-form analytical solution is normally very difficult to reach, making the use of numerical methods necessary. Markov Chain Monte Carlo (MCMC) simulation methods are used to obtain the posterior distribution by sampling from a given target probability distribution. Specifying a transition kernel for the Markov chain and starting from some initial values and iterating a large number of times, we find the target distribution. It corresponds to the limiting distribution of the Markov chain, which (should) converges in distribution to the stationary distribution of the posterior.

The Metropolis-Hastings algorithm is the sampling method used to generate draws from the posterior distribution. The algorithm samples from the region of the target distribution with highest probability but visits, as well, the entire parameter space as much as possible. It starts from an arbitrary candidate density to generate the next value of the Markov chain, then applies an acceptance/ rejection rule to decide whether this draw can be accepted as a draw of the posterior distribution. As discussed by AN and SCHORfHeide (2007), the posterior mode and the Hessian evaluated at the posterior mode are used as starting values

14 For more details, see www.princeton.edu/sims/. 
to generate draws from the posterior distribution and, in particular, to define the mean and variance of $\theta$.

The simulation strategy of the MCMC-MH algorithm is the following:

1. Consider an arbitrary candidate (or jumping) distribution

$$
S\left(\theta^{*} \mid \theta_{i-1}\right) \sim N\left(\theta_{i-1}, c \Omega_{\theta}\right)
$$

where $\theta_{i-1}$ is the last accepted draw, $c$ is a scale factor used to obtain an efficient algorithm and $\Omega_{\theta}=H\left(\theta_{m} \mid y^{\text {data }}\right)^{-1}$ is the inverse of the Hessian evaluated at the posterior mode $\theta_{m}$;

2. Draw $\theta^{*}$ from the candidate distribution;

3. Compute the acceptance rate $r$ defined as the ratio of posterior kernels evaluated at the new draw and at the last accepted draw, respectively:

$$
r=\min \left[\frac{\mathcal{K}\left(\theta^{*} \mid y^{\text {data }}\right)}{\mathcal{K}\left(\theta_{i-1} \mid y^{\text {data }}\right)}, 1\right] ;
$$

4. For each draw $i$, accept the new proposal $\theta^{*}$ with probability $r$ and maintain the last accepted draw $\theta_{i-1}$ otherwise:

$$
\theta_{i}=\left\{\begin{array}{ll}
\theta^{*} & \text { with probability } r \\
\theta_{i-1} & \text { otherwise }
\end{array} ;\right.
$$

5. Update the mean of the distribution with the new draw $\theta_{i}$;

6. Iterate on steps $2-5$ a large number of times and build a histogram of retained draws. This will eventually be the posterior distribution of $\theta$.

This acceptance rule allows to not reject too frequently the candidate draw, avoiding draws to be centered around a local maximum, and allows each move to travel a reasonable distance in the parameter space, eventually towards the global maximum. The acceptance rate, which is commonly set to lie between 20-30\%, depends on the scale factor $c$ of the candidate distribution's variance. The greater is $c$ the lower will be the acceptance rate which may cause Markov chains to concentrate too much on the tails of the posterior distribution. And the inverse is also true, the lower is $c$ the greater will be the acceptance rate and chains will likely get stuck around a local maximum. 


\section{Markov Chain Diagnostics}

The Gelman and Rubin (1992) and Brooks and Gelman (1998) statistics, for the univariate and multivariate cases, are used to assess the convergence of Markov chains. These test whether parallel chains converge to the same posterior distribution by comparing within-chain and between-chain variances. Large differences between variances may mean that chains have not converged yet and therefore a longer chain must be run, or that the posterior distribution has multiple modes and chains have converged to different modes. Different initial values for parallel chains ensure that they explore different parts of the distribution and so do not get stuck in local maxima before converging to the stationary distribution.

Using the estimated variance of the posterior distribution, defined as a weighted average of between-chain $B$ and within-chain $W$ variances of $m$ chains of length $n$,

$$
\widehat{\operatorname{Var}}(\theta)=\frac{n-1}{n} W+\frac{m+1}{n m} B
$$

we can compute the potential scale reduction factor $\hat{R}$ as:

$$
\hat{R}=\sqrt{\frac{\widehat{\operatorname{Var}}(\theta)}{W}} \text {, for the univariate case; }
$$

or

$$
\hat{R}=\sqrt{\frac{n-1}{n}+\frac{m+1}{n m} \lambda_{1}}, \text { for the multivariate case; }
$$

where $\lambda_{1}$ is the largest eigenvalue of the symmetric and positive definite matrix $W^{-1} B$. If $\hat{R}$ is large, longer simulations should be run to improve convergence because between-chain variance is substantially greater than within-chain variance. When $\hat{R}$ is close to one, it indicates that each chain $m$ has stabilized and converged to its stationary distribution since the estimated variance of the posterior distribution is close to the within-chain variance.

\section{Model Comparisons}

An and SCHORFHeIDE (2007) provide a comprehensive survey on approaches to assess model's performance. Following Smets and Wouters $(2003,2007)$ and Rabanal and Rubio-Ramírez (2005), I assess the in-sample fit of the model 
by comparing different specifications based on their marginal likelihood. From marginal likelihoods of two competing models $m_{i}$ and $m_{j}$, we can compute the ratio of posterior model probabilities or the posterior odds ratio:

$$
P O_{i, j}=\frac{p\left(m_{i} \mid y^{\text {data }}\right)}{p\left(m_{j} \mid y^{\text {data }}\right)}=\frac{L\left(y^{\text {data }} \mid m_{i}\right) p\left(m_{i}\right)}{L\left(y^{\text {data }} \mid m_{j}\right) p\left(m_{j}\right)}=B F_{i, j} \frac{p\left(m_{i}\right)}{p\left(m_{j}\right)},
$$

where the prior odds ratio is given by $p\left(m_{i}\right) / p\left(m_{j}\right)$, the relative probability of model $m_{i}$ being true with respect to $m_{j}$ a priori, and

$$
B F_{i, j}=L\left(y^{\text {data }} \mid m_{i}\right) / L\left(y^{\text {data }} \mid m_{j}\right)
$$

is the Bayes factor, the relative data density of model $m_{i}$ with respect to $m_{j}$ independently of the parameters. The Laplace approximation or the Modified Harmonic Mean Estimator is used to compute the marginal likelihood. ${ }^{15}$ Note that:

$$
L\left(y^{\text {data }} \mid m_{i}\right)=\int_{\Theta} L\left(y^{\text {data }} \mid \theta, m_{i}\right) p\left(\theta \mid m_{i}\right) d \theta,
$$

where $p\left(\theta \mid m_{i}\right)$ the prior density for model $m_{i}$. Rearranging (B.6) and considering the prior odds ratio to be one, we can compute the posterior model probabilities as:

$$
p\left(m_{i} \mid y^{\text {data }}\right)=B F_{i, j} p\left(m_{j} \mid y^{\text {data }}\right) .
$$

Using model 1 to be the denominator of the posterior model probabilities, we can rewrite the Bayes factor as

$$
B F_{i, 1}=\exp \left[\mathcal{L}\left(y^{\text {data }} \mid m_{i}\right)-\mathcal{L}\left(y^{\text {data }} \mid m_{1}\right)\right]
$$

for $i$ being each of the four models from the alternative specifications of $\lambda$ tested. Hence, we have:

15 See for example Geweke (1999). 


$$
p\left(m_{i} \mid y^{\text {data }}\right)= \begin{cases}\frac{1}{\sum_{1}^{4} B F_{k, 1}} & \text { for } i=1 \\ B F_{i, 1} p\left(m_{1} \mid y^{\text {data }}\right) & \text { otherwise. }\end{cases}
$$

Note that this methodology has limitations because it depends on the a priori beliefs the researcher has on each competing model and it is only valid to assess nested models. Thus, the outperforming model can still badly capture data dynamics and still be potentially misspecified. ${ }^{16}$

\section{Impulse Response Functions (IRFs)}

Impulse response functions are the expected response of endogenous variables to a one-time structural shock of one standard deviation in period $j$. Following Fernández-Villaverde, Rubio-Ramírez, and Sargent (2005), the model can be summarized by the following state space system: (i) the transition equation from the minimum state variable solution,

$$
x_{t+1}=E x_{t}+F u_{t}
$$

and, (ii) the measurement equation mapping the state variables to their observable counterparts,

$$
y_{t}=C x_{t}+D u_{t}
$$

where $x_{t}$ is the vector of unobserved model's state variables, $y_{t}$ the vector of the observed variables and $u_{t}$ the vector of economic shocks and measurement errors. $C$ and $D$ were defined above, and $E$ and $F$ are matrices of coefficients. For the case $D$ is full-rank so that $D^{-1}$ exists and as long as the eigenvalues of $\left(E-F D^{-1} C\right)$ are inside the unit-circle, $x_{t+1}$ can be rewritten as:

16 To evaluate the absolute performance of the model, Del Negro and Schorfheide (2004) and Del Negro et al. (2007) introduce the DSGE-VAR benchmark. They use the VAR implied by the estimated DSGE model and the respective set of cross-coefficient restrictions to construct a prior distribution for the VAR parameters. The marginal likelihood of the hyperparameter defining the prior tightness provides an overall assessment of the VAR approximation of the DSGE model. The DSGE model misspecification can be assessed by comparing the IRFs of the DSGE model and the DSGE-VAR benchmark. 


$$
x_{t+1}=\sum_{j=0}^{\infty}\left[E-F D^{-1} C\right]^{j} F D^{-1} y_{t-j} .
$$

Rearranging, we obtain an infinite order VAR representation of $y_{t}$ :

$$
y_{t}=C \sum_{j=0}^{\infty}\left[E-F D^{-1} C\right]^{j} F D^{-1} y_{t-j-1}+D u_{t} .
$$

Hence, impulse response functions from shocks $u_{t}$ to observables $y_{t}$ can be written as moving average (MA) representation given by:

$$
y_{t}=d(\mathrm{~L}) u_{t}=\sum_{j=0}^{\infty} d_{j} \mathrm{~L}^{j} u_{t}
$$

where

$$
d_{j}= \begin{cases}D & \text { for } j=0 \\ C E^{j-1} F & \text { for } j>0 .\end{cases}
$$

\section{Variance and Historical Decomposition}

Using the MA representation above, the vector of observables in period $t+h$ can be decomposed into the historical time series due to innovations in periods $t+1$ to $t+h$ (the $h$-step ahead forecast error) and into the base forecast of $y_{t+h}$ given the information available at time $t$ :

$$
y_{t+h}=\sum_{j=0}^{h-1} d_{j} u_{t+h-j}+\sum_{j=0}^{\infty} d_{j} u_{t+h-j} .
$$

Or expressing in terms of the forecast error at horizon $t+h$ :

$$
e_{t+h \mid t}=y_{t+h}-y_{t+h \mid t} \text {. }
$$

The cumulative contribution of any innovation is determined by the difference between the actual time series and the base forecast since period $t$. On the other hand, the forecast error variance decomposition (FEVD) allows to assess the importance of each shock as a source of variation to each endogenous variable at different horizons. The fraction of the forecast error variance at horizon $h$ attributable to $u_{j, t}$ of the i-th element of $e_{t+h \mid t}$ is: 


$$
\operatorname{Var}_{i j, h}=\frac{\sigma_{j}^{2} \sum_{k=0}^{h-1} d_{i j, k}^{2}}{\sum_{m=1}^{n}\left[\sigma_{m}^{2} \sum_{k=0}^{h-1} d_{i m, k}^{2}\right]},
$$

where

$$
\sum_{m=1}^{n}\left[\sigma_{m}^{2} \sum_{k=0}^{h-1} d_{i m, k}^{2}\right]
$$

is the sum of variances of the $i$-th elements of $e_{t+b \mid t}$ for each economic shock $m$.

\section{Estimation Options}

Due to computational challenges, posterior estimates are based on 100,000 draws from five parallel Markov chains (without major repercussions for chains convergence). I increased the fraction of draws to be discarded from 20 to $40 \%$. The scale used for the jumping distribution in the $\mathrm{MH}$ algorithm is set to 0.35 , implying acceptance rates around 20 to $30 \%$. A $40 \%$ initial burn-in period is considered such that any dependence on chains' starting values is removed.

\section{References}

Abel, Andrew (1990), "Asset Prices under Habit Formation and Catching Up with the Joneses", American Economic Review, 80, pp.38-42.

Adolfson, Malin, Stefan Laseén, Jesper Lindé, and Mattias VilLANi (2007), "Bayesian Estimation of an Open Economy DSGE Model with Incomplete Pass-Through", Journal of International Economics, 72, pp. 481-511.

Afonso, António, and Ricardo M. Sousa (2011), "The Macroeconomic Effects of Fiscal Policy in Portugal: A Bayesian SVAR Analysis", Portuguese Economic Journal, 10, pp.61-82.

Almeida, Vanda (2009), "Bayesian Estimation of a DSGE Model for the Portuguese Economy”, Working Paper Series N. 14, Bank of Portugal.

Almeida, Vanda, Gabriela Castro, and Ricardo M. Felix (2010), "Improving Competition in the Non-Tradable Goods and Labour Markets: The Portuguese Case", Portuguese Economic Journal, 9, pp. 163-193.

An, Sungbae, and Frank Schorfheide (2007), "Bayesian Analysis of DSGE Models", Econometric Reviews, 26, pp. 113-172. 
Bernanke, Ben S., Mark Gertler, and Simon Gilchrist (1999), "The Financial Accelerator in a Quantitative Business Cycle Framework", in Handbook of Macroeconomics, J. B. Taylor and M. Woodford, eds., vol. 1, chap. 11, pp. 1341-1393, Elsevier.

Blanchard, Olivier J., and Charles M. Kahn (1980), "The Solution of Linear Difference Models under Rational Expectations", Econometrica, 48, pp. 1305-1311.

Brooks, Stephen P., and Andrew Gelman (1998), "General Methods for Monitoring Convergence of Iterative Simulations", Journal of Computational and Graphical Statistics, 7, pp. 434-455.

Calvo, Guillermo A. (1983), "Staggered Prices in a Utility-Maximizing Framework", Journal of Monetary Economics, 12, pp. 383-398.

Campbell, John Y., and N. Gregory Mankiw (1989), "Consumption, Income and Interest Rates: Reinterpreting the Time Series Evidence", in NBER Macroeconomics Annual 1989, Volume NBER Chapters, pp. 185-246, National Bureau of Economic Research, Inc.

Canova, Fabio (2007), Methods for Applied Macroeconomic Research, Princeton, New Jersey: Princeton University Press.

Christiano, Lawrence J., Martin Eichenbaum, and Charles L. Evans (2005), "Nominal Rigidities and the Dynamic Effects of a Shock to Monetary Policy", Journal of Political Economy, 113, pp. 1-45.

Coenen, Gunter, and Roland Straub (2005), "Does Government Spending Crowd in Private Consumption: Theory and Empirical Evidence for the Euro Area", International Finance, 8, pp.435-470.

DeJong, David N., and Chetan Dave (2007), Structural Macroeconometrics, Princeton, New Jersey: Princeton University Press.

Dejong, David N., Beth F. Ingram, and Charles H. Whiteman (2000), "A Bayesian Approach to Dynamic Macroeconomics", Journal of Econometrics, 98, pp. 203-223.

Del Negro, Marco, and Frank Schorfheide (2004), "Priors from General Equilibrium Models for VARs", International Economic Review, 45, pp. 643-673.

Del Negro, Marco, Frank Schorfheide, Frank Smets, and Raf Wouters (2007), "On the Fit of New Keynesian Models", Journal of Business and Economic Statistics, 25, pp. 123-143.

Dixit, Avinash, and Joseph Stiglitz (1977), "Monopolistic Competition and Optimal Product Diversity", American Economic Review, 67, pp. 297-308. 
Erceg, Christopher J., Dale W. Henderson, and Andrew T. Levin (2000), "Optimal Monetary Policy with Staggered Wage and Price Contracts", Journal of Monetary Economics, 46,pp. 281-313.

Evans, George W., and Seppo Honkapohja (2001), Learning and Expectations in Macroeconomics, Princeton, New Jersey: Princeton University Press.

Fernández-Villaverde, Jesus, and Juan F. Rubio-Ramírez (2004), "Comparing Dynamic Equilibrium Models to Data: A Bayesian Approach”, Journal of Econometrics, 123, pp. 153-187.

Fernández-Villaverde, Jesus, Juan F. Rubio-Ramírez, and Thomas J. SarGENT (2005), “A, B, C's (and D's) for Understanding VARs”, Working Paper 9, Federal Reserve Bank of Atlanta.

Forni, Lorenzo, Libero Monteforte, and Luca Sessa (2009), "The Estimated General Equilibrium Effects of Fiscal Policy: The Case of the Euro Area", Journal of Public Economics, 93, pp. 559-585.

Galí, Jordi, J. David López-Salido, and Javier Vallés (2004), "Rule-ofThumb Consumers and the Design of Interest Rate Rules", Journal of Money, Credit, and Banking, 36, pp.739-763.

Galí, Jordi, J. David López-Salido, and Javier Vallés (2007), "Understanding the Effects of Government Spending on Consumption", Journal of the European Economic Association, 5, pp. 227-270.

Gelman, Andrew, and Donald B. Rubin (1992), "Inference from Iterative Simulation Using Multiple Sequences”, Statistical Science, 7, pp. 457-511.

Geweke, John (1999), "Using Simulation Methods for Bayesian Econometric Models: Inference, Development and Communication", Econometric Reviews, 18, pp. 1-126.

Mankiw, Gregory N. (2000), "The Savers-Spenders Theory of Fiscal Policy", American Economic Review, 90, pp. 120-125.

Milani, Fabio (2007), "Expectations, Learning and Macroeconomic Persistence", Journal of Monetary Economics, 54, pp. 2065-2082.

Mountford, Andrew, and Harald Uhlig (2004), "What Are the Effects of Fiscal Policy Shocks?”, Journal of Applied Econometrics, 24, pp. 960-992.

Otrok, Christopher (2001), "On Measuring the Welfare Costs of Business Cycles", Journal of Monetary Economics, 45, pp. 61-92.

Perotti, Roberto (1999), "Fiscal Policy in Good Times and Bad", Quarterly Journal of Economics, 114, pp. 1399-1436.

Perotti, Roberto (2004), "Estimating the Effects of Fiscal Policy in OECD Countries”, Working Paper N. 276, IGIER. 
Rabanal, Pau and Juan F. Rubio-Ramírez (2005), "Comparing New Keynesian Models of the Business Cycle: A Bayesian Approach", Journal of Monetary Economics, 52, pp. 1151-1166.

Schorfheide, Frank (2000), "Loss Function-Based Evaluation of DSGE Model", Journal of Applied Econometrics, 15, pp. 645-670.

Smets, Frank, and Raf Wouters (2003), "An Estimated DSGE Model of the Euro Area", Journal of the European Economic Association, 1, pp. 1123-1175.

Smets, Frank, and RaF Wouters (2007), "Shocks and Frictions in US Business Cycles: A Bayesian DSGE Approach”, American Economic Review, 97, pp. 586-606.

TaYlor, John B. (1980), "Aggregate Dynamics and Staggered Contracts", Journal of Political Economy, 88, pp. 1-23.

Yun, Tack (1996), "Nominal Price Rigidity, Money Supply Endogeneity and Business Cycle", Journal of Monetary Economics, 37, pp.345-370.

\section{SUMMARY}

A New Keynesian DSGE model with non-Ricardian households is estimated for the Portuguese economy and the stability of the model's prediction (posterior distributions, impulse responses, and sources of fluctuations in endogenous variables) tested under different assumptions on non-Ricardian households. Their share is estimated to be relatively high (58\%). Furthermore, estimates of several parameters as well as the magnitude and persistence of shocks are particularly sensitive to the share of non-Ricardian households. Impulse responses to consumption preference and productivity shocks are amplified for lower shares; for greater proportions, the model predicts more noticeable responses to price markup and government spending shocks. Fluctuations in output growth are mainly driven by productivity shocks for a lower share and by price markup shocks in the opposite scenario. A high proportion of these households together with a high degree of price stickiness lead the Taylor-type interest rate rule solution to be locally indeterminate. 